\title{
Irish adults transition to retirement - wellbeing, social participation and health-related behaviours. Findings from The Irish Longitudinal Study on Ageing (TILDA)
}

Mark Ward

Edited by: Christine McGarrigle and Orna Donoghue 
Copyright (C) The Irish Longitudinal Study on Ageing 2019

The Irish Longitudinal Study on Ageing

Lincoln Place

Trinity College Dublin

Dublin 2

Tel: +35318962509

Email: tilda@tcd.ie

Website: www.tilda.ie

https://www.doi.org/10.38018/TildaRe.2019-00 
An Roinn Sláinte

DEPARTMENT OFHEALTH
The

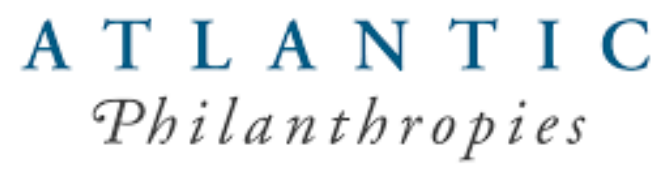

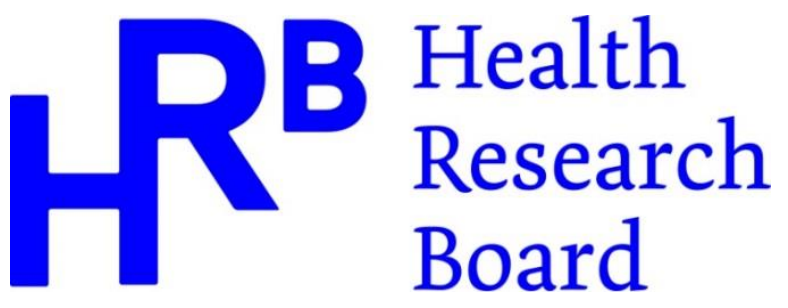

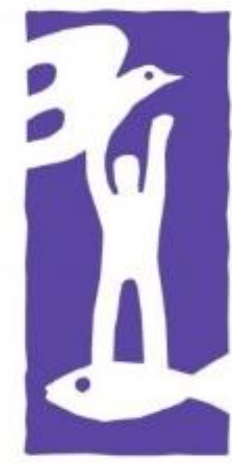

Irish Life

\section{Acknowledgements}

We would like to acknowledge the vision and commitment of our funders, Irish Life, The Atlantic Philanthropies and the Department of Health, which is providing funding on behalf of the state. We would also like to state that any views expressed in this report are not necessarily those of the Department of Health or of the Minister of Health. We would also like to thank the TILDA participants without whom this research would not be possible. 


\section{Key findings}

- Retirement is associated with considerable adjustments to financial, physical and mental wellbeing, daily activities, and health-related behaviours.

- In $200950 \%$ of TILDA participants aged 50 to 67 years were employed (employee or selfemployed) and $18 \%$ were retired.

- More than half (58\%) of employed participants planned to retire before they reached 68 years while $22 \%$ did not plan to retire at any time.

- Almost half (49\%) of employed participants were members of an occupational pension scheme organised by their employer, and $13 \%$ were members of a Personal Retirement Saving Account scheme or other personal pension scheme. The remainder were not members of either.

- Employed participants aged between 61 and 68 years in 2009 were the most likely group to have retired between 2009 and 2016 .

- Pension eligibility was the most commonly cited reason for retirement (34\%) while $10 \%$ retired due to ill-health.

- Thirteen percent of retirees continued to work after their retirement, typically in temporary or occasional positions for an average of 23 hours per week.

- Overall, quality of life was high among TILDA participants and increased from an average score of 27.9 at age 50 to a peak of 29.6 at age 68 .

- There was little overall change in average quality of life score between employment and retirement, though $44 \%$ of employed participants did report some improvement in quality of life when they retired.

- There was no change in perceived stress following retirement.

- Thirty eight percent of employed participants volunteered at some time in the last year at Wave 1. There was no significant change in the percentage who volunteered following 
retirement. However, those who did volunteer while employed tended to do so more often once retired.

- Participation in weekly active and social leisure activities increased after retirement. Three quarters of participants took part in at least one activity each week while employed and this increased to $83 \%$ after retirement.

- While rates of social participation are high, efforts to increase volunteering and social participation among older adults should be encouraged as these activities provide benefits not only to the participants themselves but to society more generally.

- $\quad$ Fifty four percent of participants in employment provided care for grandchildren and this changed little post-retired. However, the average number of hours of grandchildren care increased from 28 hours to 38 hours per week.

- There was no significant change in the percentage of employed participants who provided help to a parent for ADLs or IADLs once retired.

- $\quad$ Retirement was not associated with any change in the prevalence of smoking.

- Retirement marks a time of change in the lives of individuals and therefore provides opportunities as well as challenges to many aspects of people's lives. Future research should continue to track these changes over the longer term. 


\section{Contents}

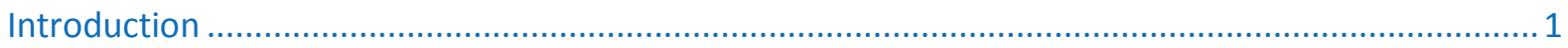

Methodology

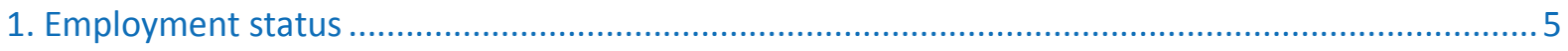

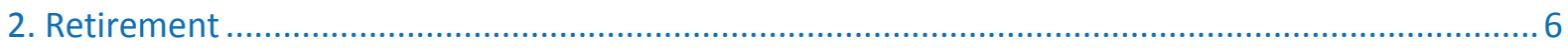

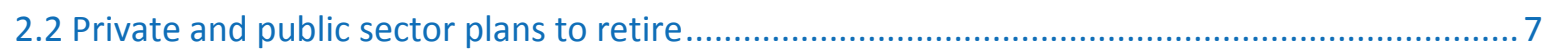

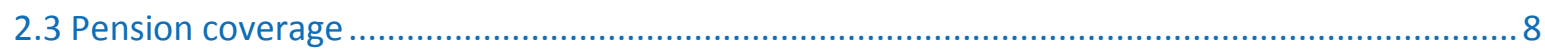

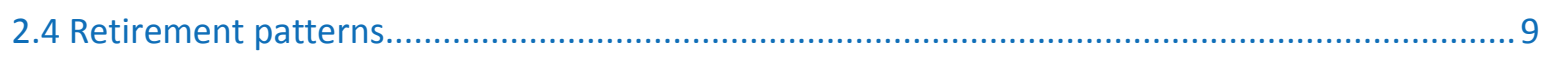

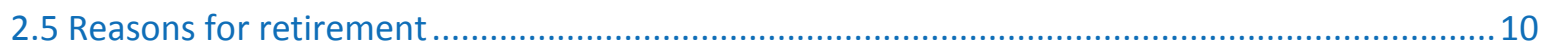

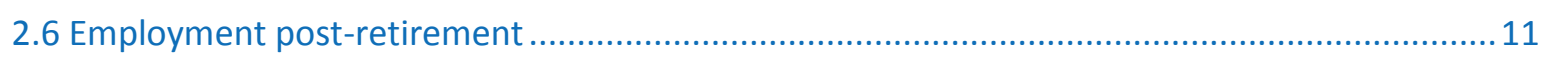

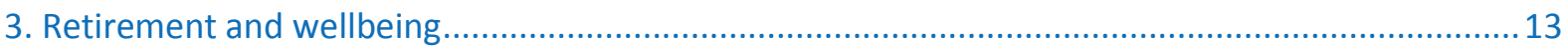

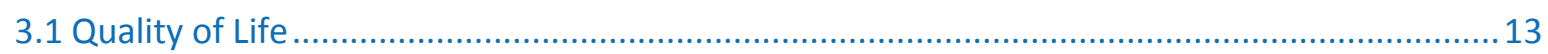

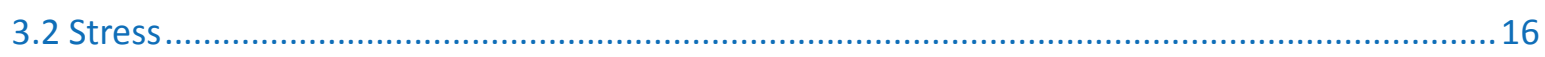

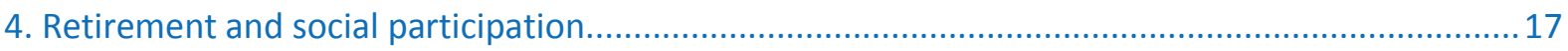

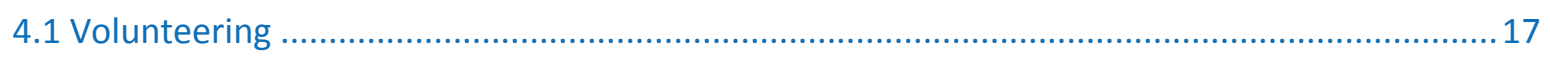

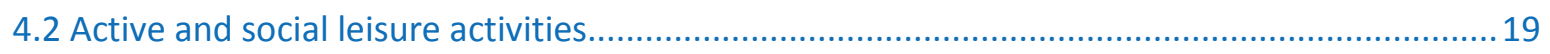

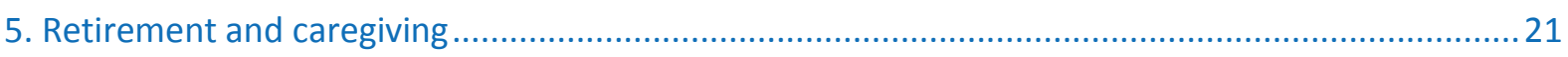

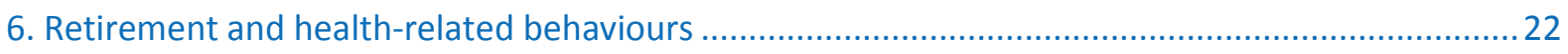

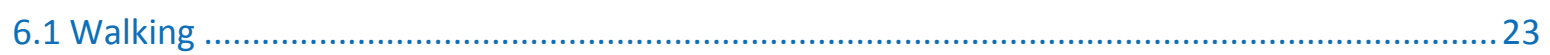

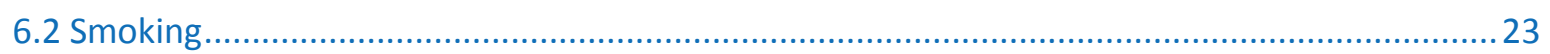

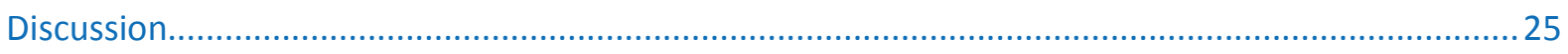

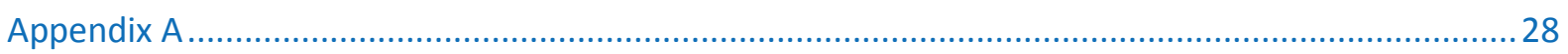

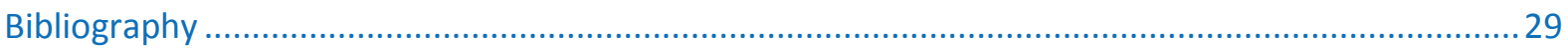

Table 1. Labour market status of TILDA participants aged less than 68 years at Wave 1, by sex and

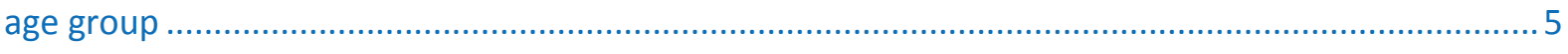

Table 2. Age at which participants plan to retire, by gender and age group ......................................

Table 3. Percentage of retired participants who did some paid employment during the last week, by

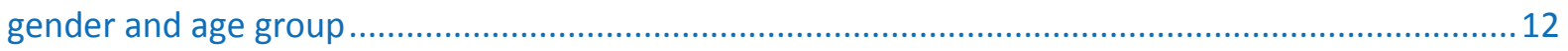

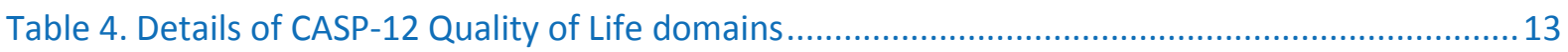

Table 5. Mean CASP-12 QoL score before and after retirement by gender, age, and whether retirement was planned for 
Table 6. Mean CASP-12 QoL domain scores before and after retirement by gender

Table 7. Mean Perceived Stress Score before and after retirement by gender, age, and whether retirement was planned for

Table 8. Percentage who volunteered at least weekly before and after retirement by gender, age, and whether retirement was planned for

Table 9. Weekly active and social leisure activities before and after retirement ......

Table 10. Weekly active and social leisure activities before and after retirement by urban / rural ....21

Table 11. Percentage and number of hours cared for grandchildren or parents with an ADL or IADL before and after retirement

Table 12. Average minutes walking per week and percentage exceeding the recommended 150+ minutes per week activities before and after retirement

Figure 1. Percentage of men and women aged less than 68 years and employed in the public or private sector $(n=2154)$.......

Figure 2. Age at which participants aged less than 68 years and employed, plan to retire by gender and employment sector $(n=2007)$.....

Figure 3. Pension coverage of participants aged $<68$ years and employed at Wave 1 , by age intending to retire $(n=2090)$

Figure 4. Change in employment status among participants employed at Wave 1 and aged $<68$ years $(n=1244)$ .10

Figure 5. Reasons for retirement by whether or not participants had planned to retire $(n=225) \ldots \ldots .11$

Figure 6. Change in quality of life (CASP-12) score over seven years from Wave 1 to Wave 4............14

Figure 7. Mean CASP-12 Quality of Life score at each Wave by timing of retirement ........................15

Figure 8. Percentage of participants who volunteered before and after retirement .........................18

Figure 9. Change in frequency of volunteering among participants who volunteered at Wave 1 and

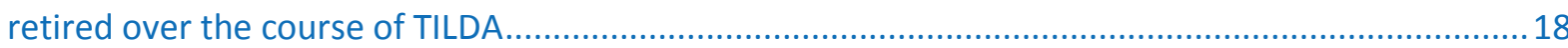

Figure 10. Percentage of participants who smoked at each Wave before and after retirement.........24 


\section{Introduction}

The Irish Longitudinal Study on Ageing (TILDA) has collected detailed survey and health assessment data from adults aged 50 years and older in the Republic of Ireland since 2009. As part of the survey data collection that is carried out every two years, TILDA collects comprehensive information on participants' employment status and their transition to retirement. As TILDA is a longitudinal study that collects information from the same participants during each round of data collection, it provides us with a unique opportunity to observe changes in the lives of older adults as they age and embark on new stages of their life-cycle. Employment is oftentimes central to an individual's identity and the transition from employment to retirement is understandably a disruptive event that necessitates alterations to daily routines, social roles, relationships, and indeed self-identity [1]. While the financial implications of retirement are well documented, including by TILDA [2,3], less is known of the effect of retirement on the social interactions and activities of Irish adults as they move from employment to retirement. To address this gap in knowledge, this report describes retirement patterns in Ireland and examines the effect that retirement has on a number of social activities and wellbeing more generally.

Among the many consequences of retirement, it can result in major adjustments to daily activities and wellbeing [4], including changes in patterns of social participation. Alternatively, retirement may have positive consequences including increased social participation and improved mental health and wellbeing, as people have more freedom to spend their time as they choose [5]. Whether retirement entails increased social activities or a retreat from social outlets may depend on how prepared individuals are for retirement, the nature of their retirement, and financial security post-retirement. For example, a greater sense of control over the decision to retire, rather than being forced to do so, is associated with more positive outcomes $[6,7]$.

Retirement is often accompanied by positive changes to health-related behaviours such as quitting smoking [8] and increasing physical activity, although this association can vary according to whether individuals retired from sedentary or physically active occupations $[9,10]$. 
This report is organised into a number of sections wherein we describe employment and retirement patterns among the TILDA cohort and also examine the relationship between retirement from the labour market and wellbeing, social participation, and health related behaviours. The specific sections are:

- Employment status;

- Retirement;

- Retirement and wellbeing;

- Retirement and social participation;

- Retirement and caregiving;

- Retirement and health related behaviours.

\section{Methodology}

TILDA is a prospective nationally representative study on ageing in the Republic of Ireland. TILDA collects information on all aspects of health, economic and social circumstances from communitydwelling people aged 50 and over in a series of data collection waves carried out every two years. Participants were selected using multi-stage stratified random sampling whereby 640 geographical areas, stratified by socio-economic characteristics, were selected, followed by 40 households within each area. The Irish GeoDirectory listing of all residential addresses provided the sampling frame. The first Wave of data collection was conducted between October 2009 and July 2011 and a total of 8,504 participants were recruited. This represents 1 in 156 people aged 50 and over in Ireland (at Wave 1).

TILDA employs three modes of data collection: computer-assisted personal interview (CAPI) administered by trained social interviewers in the participants' own homes; a self-completion questionnaire (SCQ) completed privately by the participant and designed for the collection of more sensitive information such as alcohol use and relationships; and a health assessment carried out by research nurses at Waves 1 and 3.

To account for systematic differences in participation among different sub-groups and to ensure that the estimates derived from the sample remain representative of the target population, appropriate survey weights were applied to ensure that sub-groups within the sample are represented proportionate to the number of that subgroup present in the population of Ireland. 
Sample

Analyses were limited to those aged less than 68 years at Wave one $(n=5,445)$ to reflect the fact that changes announced by the Irish government to the Irish pension system in 2010 resulted in the State pension age increasing from 65 years to 66 in 2014, 67 in 2021 and 68 in 2028 [11].

Sample

TILDA collects detailed information on wide range of aspects of the lives of older adults including employment, retirement, and social activities. As this information is collected at each round of data collection, we are able to observe changes in participation over a seven year period and importantly, examine whether any differences exist in the participation of individuals before and after retirement.

The first round of data collection by TILDA took place in 2009/2011 while the fourth Wave was conducted in 2016. Analyses were limited to those aged less than 68 years at Wave 1 . This decision to limit our analyses to this age group was informed by the fact that changes announced by the Irish government in 2010 to the Irish pension system resulted in the State pension age increasing from 65 years to 66 in 2014, 67 in 2021 and 68 in 2028 [11]. Our analyses therefore follows this group of participants over a seven year period.

\section{Main outcome measures used in the report}

In TILDA, detailed information is collected on participants' current or previous occupation, at each Wave of data collection. Participants who describe themselves as being an employee of selfemployed are subsequently asked a number of questions about any arrangements they have made for retirement, including any pension arrangements that they have in place. Participants who have already retired from the labour market are asked to provide details about their work history and the timing and reasons for retirement. In this report, we consider two types of social participation volunteering; and active and social leisure activities - and examine if they are impacted by retirement from paid employment. As part of the SCQ, participants were asked whether they ever volunteered during the last year and if so, how often they did so: at least once per week; at least once per month; a few times a year or less; and, never.

Participation in a wide range of active and social leisure activities was recorded and these activities are then grouped into a four domains using a classification scheme defined by House et al. [12]. Our analysis of these activities is limited to one of the four activity domains, participation in active and social leisure activities. Active and social leisure activities include going to films, plays or concerts; 
attending classes or lectures; playing cards, bingo, games in general; going to the pub; eating out of the house; taking part in sport activities or exercise.

As well as different types of social participation, this report is also interested in possible changes to other aspects of peoples' lives once they retire. Participants were asked if they have provided childcare for at least one hour per week in the last two years, and if so, for how many hours they provide care in an average week. Participants were also asked to provide information on the number of days they walked in the last week and the number of hours and minutes they walked on those days. Specifically, participants were instructed to think about the time you spent walking in the last 7 days. This includes at work and at home, walking to travel from place to place, and any other walking that you might do solely for recreation, sport, exercise, or leisure. They were then asked on how many days in the last seven, did they walk for at least 10 minutes at a time, and for how long did they usually spend walking on those days. The number of days is then multiplied by the number of minutes to give us a total number of minutes that participants walked for in the last week. 


\section{Employment status}

As shown in Table 1, 50\% of all participants aged less than 68 years at Wave 1 were employed (employee or self-employed), $18 \%$ were retired, $14 \%$ looked after the family home on a full-time basis, while the remaining $17 \%$ were unemployed, in full-time education or training, or permanently sick or disabled. A higher percentage of men were employed compared to women ( $57 \%$ vs. $42 \%$ ) while women were significantly more likely to be engaged full-time in looking after the family home ( $27 \%$ vs. $1 \%)$.

Table 1. Labour market status of TILDA participants aged less than 68 years at Wave 1, by sex and age group

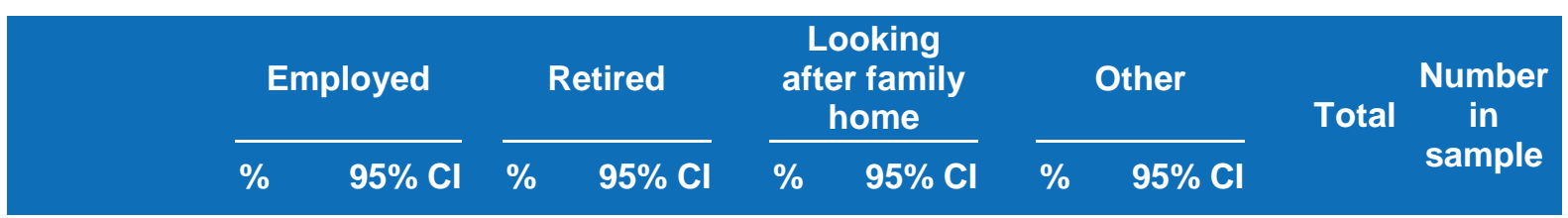

Male

\begin{tabular}{lllllllllll}
$50-55$ years & 74 & {$[71-77]$} & 3 & {$[2-4]$} & 2 & {$[1-3]$} & 21 & {$[18-24]$} & 100 & 870 \\
\hline $56-60$ years & 61 & {$[57-64]$} & 13 & {$[11-16]$} & 1 & {$[0-2]$} & 26 & {$[23-29]$} & 100 & 715 \\
$61-67$ years & 36 & {$[33-40]$} & 47 & {$[44-51]$} & 1 & {$[0-2]$} & 16 & {$[13-19]$} & 100 & 873 \\
Total & 57 & {$[55-59]$} & 21 & {$[19-23]$} & 1 & {$[1-2]$} & 21 & {$[19-22]$} & 100 & 2458
\end{tabular}

Female

$\begin{array}{lllllllllll}50-55 \text { years } & 57 & {[54-60]} & 3 & {[2-4]} & 22 & {[19-25]} & 18 & {[16-21]} & 100 & 1101 \\ 56-60 \text { years } & 46 & {[42-49]} & 11 & {[9-14]} & 28 & {[25-32]} & 14 & {[12-17]} & 100 & 876 \\ 61-67 \text { years } & 24 & {[22-27]} & 34 & {[31-37]} & 32 & {[29-35]} & 10 & {[8-12]} & 100 & 1010 \\ \text { Total } & 42 & {[41-44]} & 16 & {[14-17]} & 27 & {[26-29]} & 14 & {[13-16]} & 100 & 2987\end{array}$

Total

$\begin{array}{lllllllllll}50-55 \text { years } & 66 & {[63-68]} & 3 & {[2-4]} & 12 & {[10-13]} & 20 & {[18-21]} & 100 & 1971 \\ 56-60 \text { years } & 53 & {[51-56]} & 12 & {[11-14]} & 14 & {[13-16]} & 20 & {[18-23]} & 100 & 1591 \\ 61-67 \text { years } & 30 & {[28-33]} & 40 & {[38-43]} & 17 & {[15-18]} & 13 & {[11-15]} & 100 & 1883 \\ \text { Total } & 50 & {[48-51]} & 18 & {[17-20]} & 14 & {[13-15]} & 17 & {[16-19]} & 100 & 5445\end{array}$

As shown in Figure 1, most participants who were employed, worked in the private sector $(57 \%, 95 \%$ $\mathrm{Cl}$ : 53.5-59.5). While a similar percentage of women worked in the private and public sector, men were more likely to work in the private sector. 
Figure 1. Percentage of men and women aged less than 68 years and employed in the public or private sector $(n=2154)$
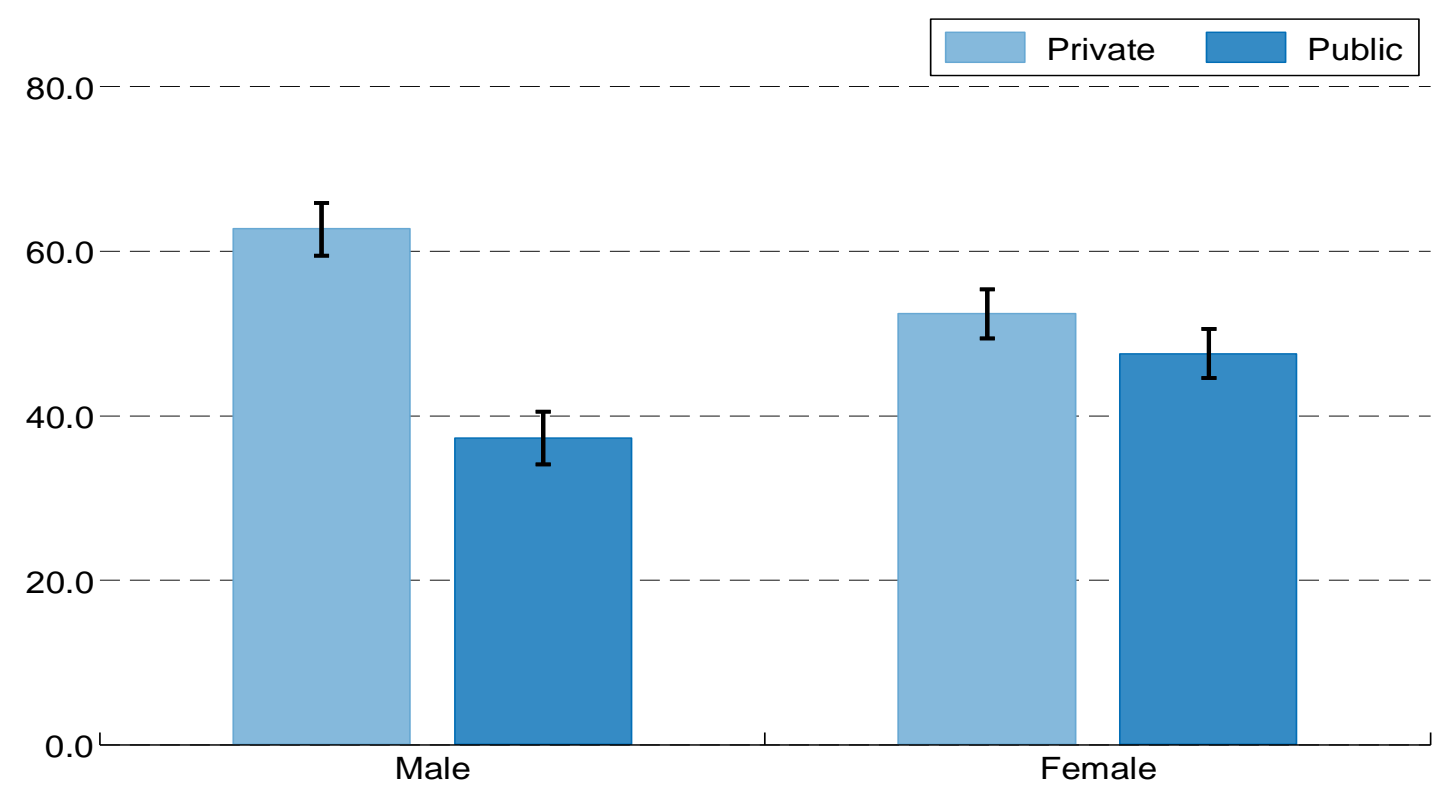

\section{Retirement}

While retirement is often framed as simply an age-related process, it is in fact a more complex process that can happen at different ages, for different reasons, and in different contexts. To capture some of these differences among Irish adults, we describe planning for retirement; pension coverage; retirement patterns; the timing of and reasons for retirement; and importantly, employment post-retirement.

\subsection{Planning for retirement}

Participants, who were currently employed (including employees and self-employed) and those who were unemployed or in education or training, were asked to state the age at which they plan to retire. The age at which employed participants intend to retire were grouped into five categories: less than 65 years, 65 to 67 years, and 68 years and older, no plans to retire, and don't know. It has been shown previously that individuals who do not know at what age they hope to retire often face more uncertainty in their future labour market participation and these individuals are also more likely to have experienced a more variable or less secure employment history [11]. Therefore, participants who reported that they did not know when they planned to retire are likely to differ from those who are planning their retirement in terms of their employment histories and futures. 
Table 2 shows that most participants (58\%) who were employed at Wave 1 planned to retire before the age of 68 years while $6 \%$ (95\% Cl: $5-7)$ intended to retire after 67 years. Despite this, a sizeable proportion (22\%, $95 \% \mathrm{Cl}: 20-40)$ of participants reported that they had no plans to retire while a further $14 \%$ did not know when they would retire. On average, women planned to retire earlier than men while men were significantly more likely than women to say that they have no plans to retire (25\% vs. $19 \%)$.

Table 2. Age at which participants plan to retire, by gender and age group

\begin{tabular}{|c|c|c|c|c|c|c|c|c|c|c|}
\hline$<65$ years & & $\begin{array}{l}\text { j5-67 } \\
\text { ears }\end{array}$ & & years & & $\begin{array}{l}\text { 't plan } \\
\text { retire }\end{array}$ & & t know & Total & $\begin{array}{c}\text { Number } \\
\text { in }\end{array}$ \\
\hline$\% \quad 95 \% \mathbf{C l}$ & $\%$ & $95 \% \mathrm{Cl}$ & $\%$ & $95 \% \mathrm{Cl}$ & $\%$ & $95 \% \mathrm{CI}$ & $\%$ & $95 \% \mathrm{Cl}$ & & sample \\
\hline
\end{tabular}

Male

\begin{tabular}{|c|c|c|c|c|c|c|c|c|c|c|c|}
\hline $50-55$ years 21 & [19-24] & 38 & [35-42] & 6 & {$[5-8]$} & 22 & [19-26] & 12 & [10-15] & 100 & 778 \\
\hline $56-60$ years 13 & [11-17] & 41 & [37-46] & 5 & {$[4-8]$} & 27 & [24-31] & 13 & [10-16] & 100 & 542 \\
\hline $61-67$ years 3 & [2-6] & 46 & [40-51] & 10 & {$[7-14]$} & 26 & [21-32] & 15 & [11-20] & 100 & 341 \\
\hline Total & [13-17] & 41 & [38-43] & 7 & {$[5-8]$} & 25 & [22-27] & 13 & [11-15] & 100 & 1661 \\
\hline
\end{tabular}

Female

\begin{tabular}{|c|c|c|c|c|c|c|c|c|c|c|c|c|}
\hline $50-55$ years & 31 & [27-34] & 32 & [29-36] & 4 & {$[3-6]$} & 15 & [12-18] & 18 & [15-21] & 100 & 749 \\
\hline $56-60$ years & 21 & [17-25] & 43 & [38-48] & 3 & {$[2-6]$} & 20 & [17-25] & 13 & {$[10-16]$} & 100 & 474 \\
\hline $61-67$ years & & [4-9] & 45 & [39-51] & 8 & [5-12] & 26 & [21-32] & 15 & [11-20] & 100 & 286 \\
\hline Total & 23 & [20-25] & 38 & [36-41] & 5 & [4-6] & 19 & [17-21] & 16 & [14-18] & 100 & 1509 \\
\hline
\end{tabular}

\begin{tabular}{|c|c|c|c|c|c|c|c|c|c|c|c|}
\hline $50-55$ years 25 & [23-28] & 36 & [33-38] & 5 & [4-7] & 19 & [17-22] & 14 & [13-16] & 100 & 1527 \\
\hline $56-60$ years 16 & {$[14-19]$} & 42 & [39-45] & 5 & [3-6] & 25 & [22-28] & 13 & [11-15] & 100 & 1016 \\
\hline $61-67$ years 4 & {$[3-6]$} & 46 & {$[41-50]$} & 9 & [7-12] & 26 & [22-30] & 15 & [12-19] & 100 & 627 \\
\hline Total & {$[17-20]$} & 40 & [38-42] & 6 & {$[5-7]$} & 22 & [20-24] & 14 & [12-16] & 100 & 3170 \\
\hline
\end{tabular}

Note. $\mathrm{Cl}=$ confidence interval

\subsection{Private and public sector plans to retire}

In general, public sector occupations are more likely than those in the private sector to be permanent and pensionable. Furthermore, 15\% of TILDA participants were self-employed and therefore responsible for their own pension and retirement planning. In light of these differences, here we briefly describe differences in the age at which participants planned to retire according to the sector (public / private) in which they worked. Figure 2 shows that 65 to 67 years of age was the 
most popular planned age at which to retire among men and women working in both the public and private sectors. Public sector employees planned to retire at an earlier age than private sector employees (including self-employed. Participants who worked in the public sector were significantly more likely to have plans to retire from paid employment.

Figure 2. Age at which participants aged less than 68 years and employed, plan to retire by gender and employment sector $(n=2007)$

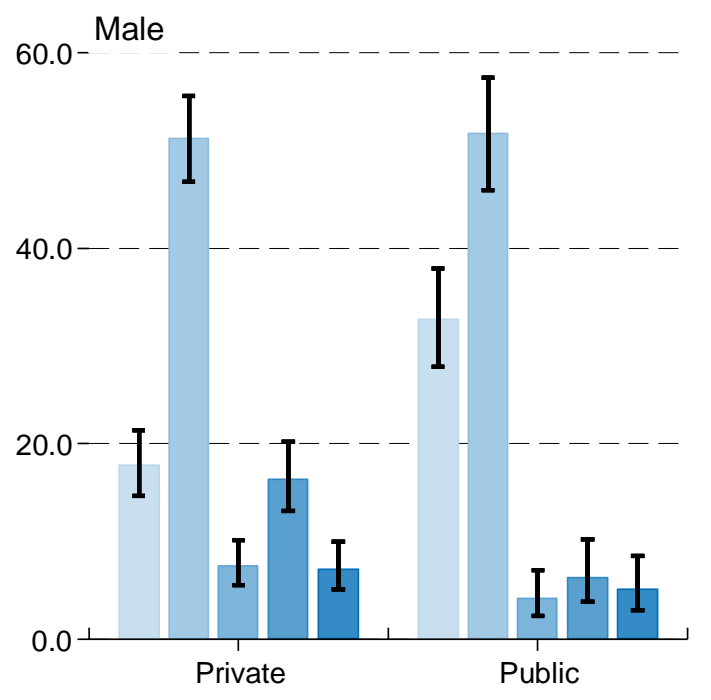

$<65$ years

Don't plan to retire
Female

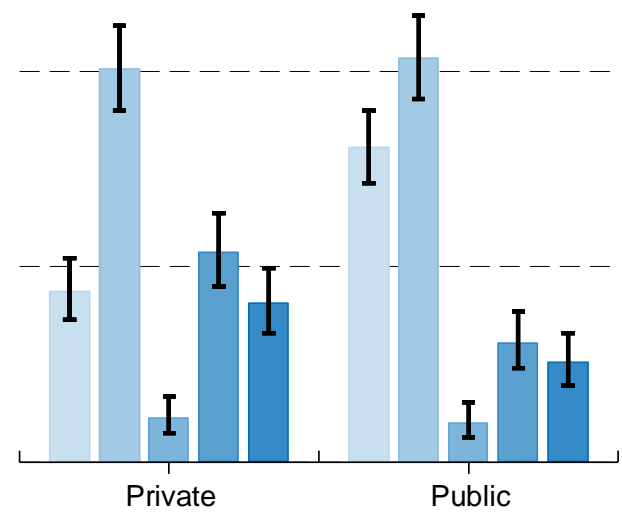

65-67 years

$68+$ years

Don't know

\subsection{Pension coverage}

Participants employed in both the public and private sector were asked if they were covered by an occupational pension scheme organised by their current or previous employer, a Personal Retirement Saving Account (PRSA) organised through their current employer, or another kind of personal pension scheme. If respondents were covered by both an occupational and personal pension scheme, they were classed as having an occupational pension.

Figure 3 shows the percentage of respondents who had no pension coverage, were covered by an occupational pension, or a PRSA/other personal pension. This has been further broken down by the age at which they planned to retire. Almost half (48.9\%, 95\%Cl: 46.4-51.3) were members of an occupational pension scheme organised by their employer, and $12.8 \%$ (95\% $\mathrm{Cl}$ : 11.2-14.5) were members of a Personal Retirement Saving Account scheme organised through their employer. The remainder had no pension. 
Interestingly, those planning to retire at an earlier age were significantly more likely than others to be a member of an occupational pension scheme. Conversely, almost $60 \%$ of workers with no plans to retire had no pension.

Figure 3. Pension coverage of participants aged $<68$ years and employed at Wave 1 , by age intending to retire $(n=2090)$

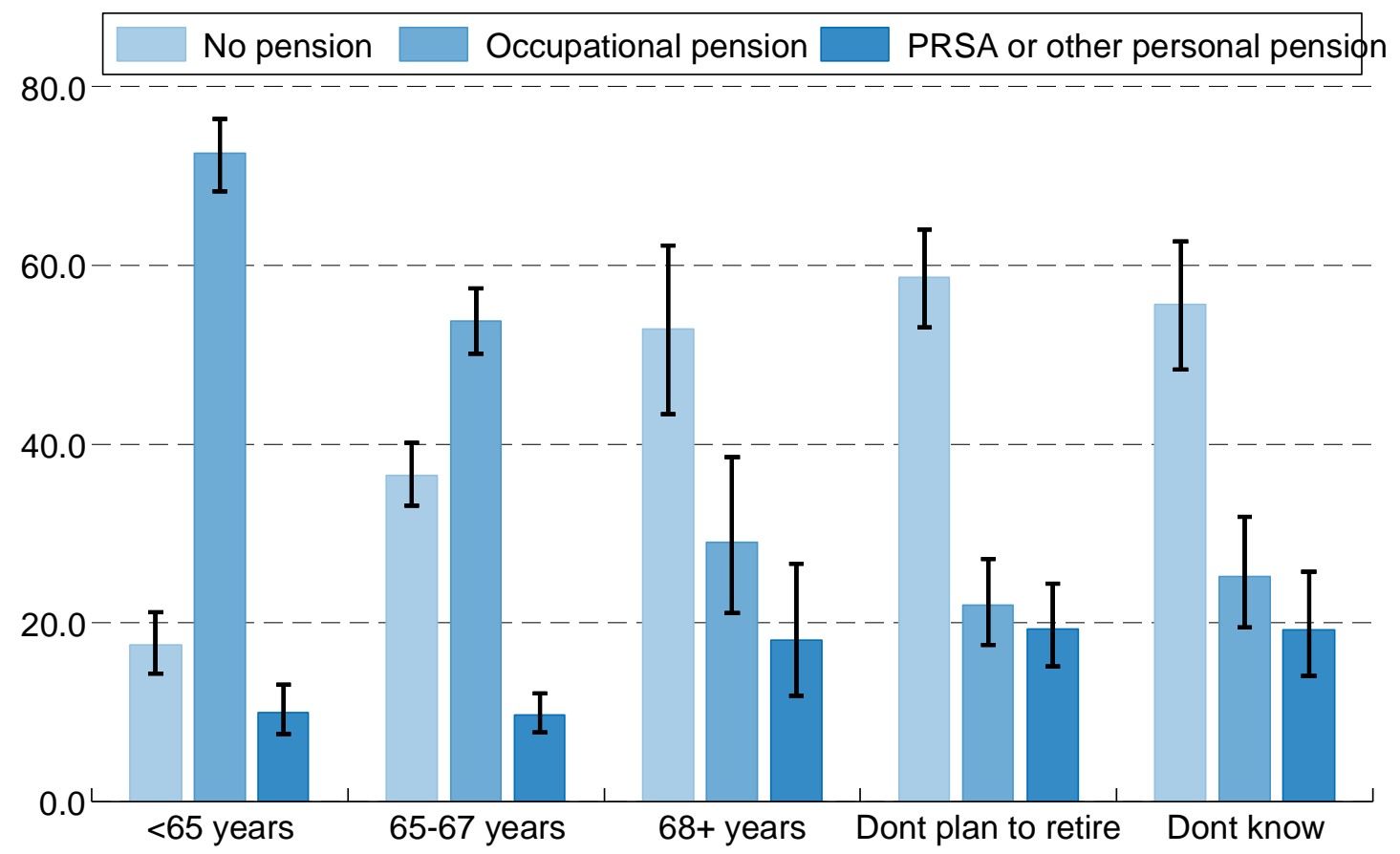

\subsection{Retirement patterns}

Next, we describe the transition from employment to retirement including the timing of and reasons for retirement. This analysis is limited to participants for whom data on employment status is available at all four Waves of TILDA. Furthermore, only those who reported that they were employed or retired at some point over the four Waves were included. This means that those participants who reported at Wave 1 that they were in 'full-time education'; 'permanently sick or disabled'; or 'looking after home or family', were not included in the analysis.

Figure 4 shows that most participants aged 50 to 55 years, were employed at each of the four Waves. In contrast, those aged between 61 to 67 years were most likely to have retired from paid employment during this period, which is unsurprisingly given that the current statutory retirement age falls at this time. This pattern was similar for both men and women although a significantly higher percentage of men aged 61-67 years were employed across all four Waves (37.6\% of men vs. $17.5 \%$ of women). 
Figure 4. Change in employment status among participants employed at Wave 1 and aged $<68$ years $(n=1244)$
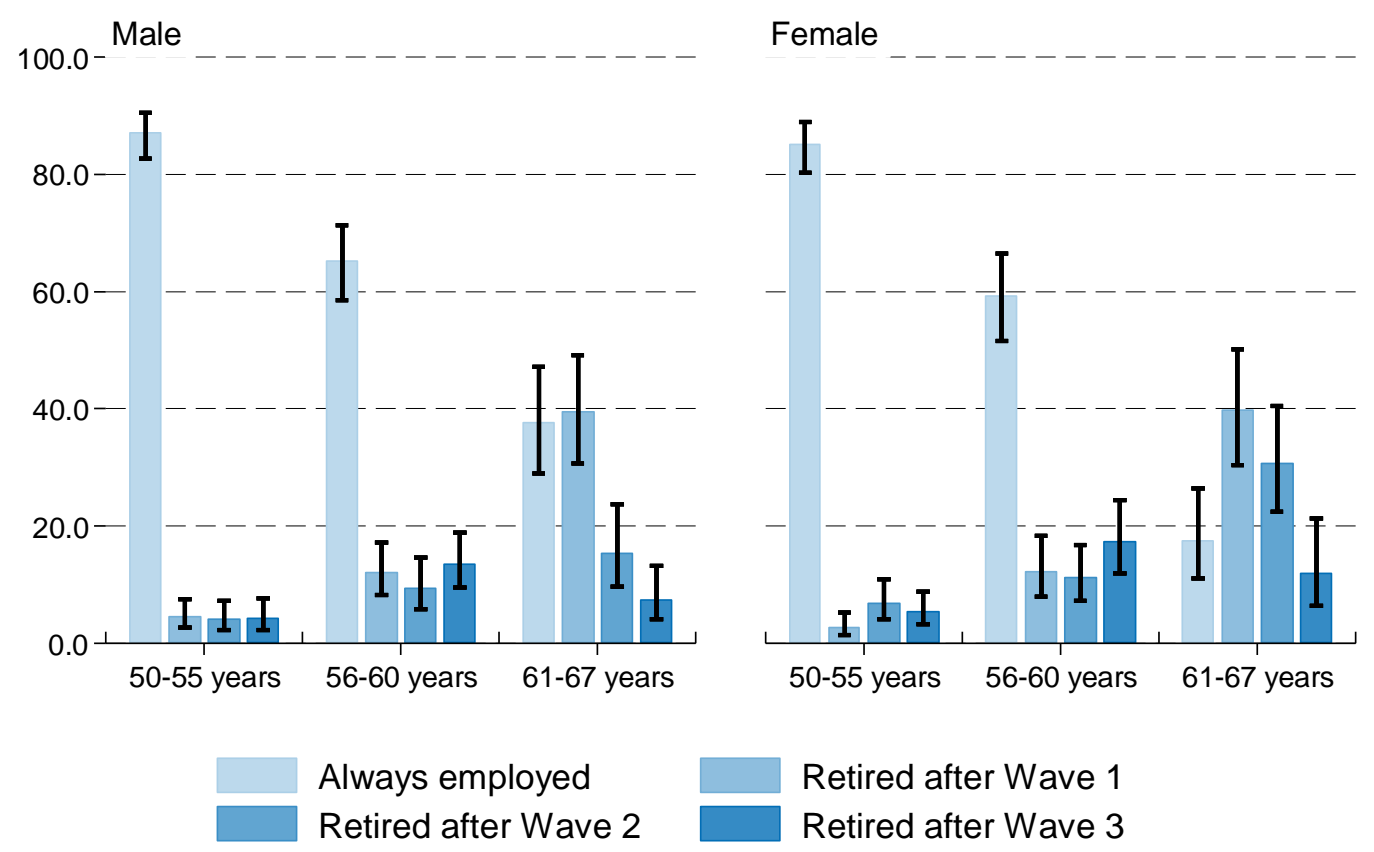

\subsection{Reasons for retirement}

Once participants reported that they were retired, they were asked about the reason for their retirement. The response categories available to them were: became eligible for a state pension; became eligible for an occupational pension; became eligible for a private pension or annuity; made redundant; own ill health; ill health of relative or friend; to retire at same time as spouse or partner; to spend more time with family; to enjoy life. For clarity, this list was re-grouped into: became eligible for pension; ill health (own or relative/friend); made redundant; other reasons including those related to quality of life.

Figure 5 shows that among those who retired, more than half $(57.2 \% ; 95 \% \mathrm{Cl}: 50.0-64.1)$ reported that they retired when they became eligible for a pension (state, occupational, or private) while one third (33.5\%; 95\% Cl: 27.4-40.1) retired due to other reasons such as spending time with family or enjoying life. The remainder retired due to ill-health (4.9\%; $95 \% \mathrm{Cl}: 2.5-9.4)$ or were made redundant (4.5\%; 95\% Cl: 2.3-8.5). Becoming eligible for a pension was the biggest driver of retirement among participants who had planned for retirement. A larger percentage of participants who had not planned to retire did so due to ill-health, compared to those who had retirement plans. 
Figure 5. Reasons for retirement by whether or not participants had planned to retire $(n=225)$
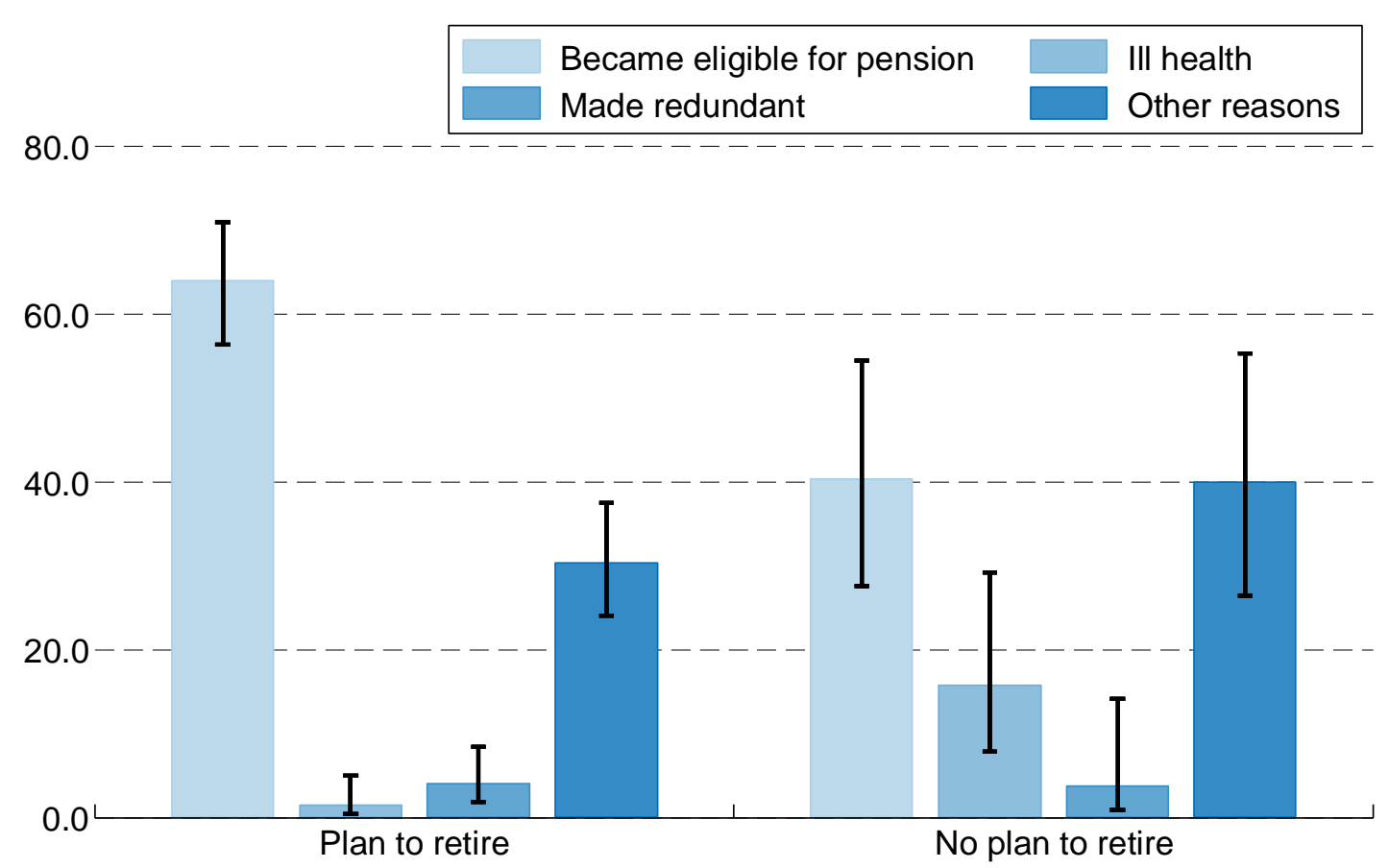

\subsection{Employment post-retirement}

Retired participants were asked if they did "any paid work during the last week, either as an employee or self-employed, for at least one hour?" As shown in Table 3,13\% of retirees did one hour or more of paid work in the previous week with men $(17 \%, 95 \% \mathrm{Cl}: 12-23)$ significantly more likely than women (8\%, 95\% Cl: 5-12) to work after retirement. There were no clear differences in the likelihood of continuing to work after retirement according to age. In almost all cases, employment post-retirement was described as temporary or occasional work. The average numbers of hours worked in a typical week was 22.7 (95\% Cl: 18.4-27.0). 
Table 3. Percentage of retired participants who did some paid employment during the last week, by gender and age group

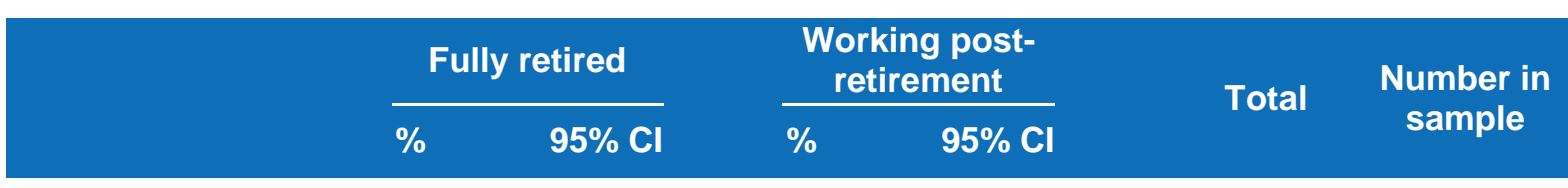

\section{Male}

$\begin{array}{lllllll}50-55 \text { years } & 84 & {[69-92]} & 16 & {[8-31]} & 100 & 37 \\ 56-60 \text { years } & 86 & {[76-92]} & 14 & {[8-24]} & 100 & 75 \\ 61-67 \text { years } & 80 & {[69-88]} & 20 & {[12-31]} & 100 & 81 \\ \text { Total } & 83 & {[77-88]} & 17 & {[12-23]} & 100 & 193\end{array}$

Female

\begin{tabular}{lllllll}
$50-55$ years & 91 & {$[80-96]$} & 9 & {$[4-20]$} & 100 & 45 \\
\hline $56-60$ years & 93 & {$[85-97]$} & 7 & {$[3-15]$} & 100 & 81 \\
$61-67$ years & 91 & {$[84-96]$} & 9 & {$[4-16]$} & 100 & 95 \\
Total & 92 & {$[87-95]$} & 8 & {$[5-12]$} & 100 & 221
\end{tabular}

Total

\begin{tabular}{lllllll}
$50-55$ years & 87 & {$[78-93]$} & 13 & {$[7-22]$} & 100 & 82 \\
\hline $56-60$ years & 89 & {$[83-93]$} & 11 & {$[7-17]$} & 100 & 156 \\
$61-67$ years & 86 & {$[78-91]$} & 14 & {$[9-22]$} & 100 & 176 \\
Total & 87 & {$[83-90]$} & 13 & {$[10-17]$} & 100 & 414
\end{tabular}

Note. $\mathrm{Cl}=$ confidence interval 


\section{Retirement and wellbeing}

\subsection{Quality of Life}

Increased life expectancy over the last number of decades has led to an increased interest in the quality of life of older adults $[13,14]$. This has resulted in our conceptualisation of quality of life being broadened to include a more holistic assessment of wellbeing beyond the previously narrow definition which focused almost exclusively on the absence or presence of ill-health. Quality of life (QoL) was measured at each Wave of data collection in TILDA using the previously validated Control, Autonomy, Self-realisation and Pleasure Scale (CASP-12) measurement tool $[15,16]$ which captures information on four domains of the QoL of older adults (Table 4). The items included in CASP-12 consist of statements such as: I can do the things that I want to do, I look forward to each day, and I feel that life is full of opportunities. Participants are asked to indicate how often (often, sometimes, not often, or never) they feel each statement applies to their life. Each item is scored from 0 to 3 and summed to give an overall score (range 0 to 36 ) with higher scores denoting better QoL. The full list of items included in CASP-12 are provided in Appendix A (Table A.1).

Table 4. Details of CASP-12 Quality of Life domains

\begin{tabular}{ll} 
Control & The ability to actively participate in one's environment. \\
\hline Autonomy & The right of the individual to be free from the unwanted interference of others. \\
\hline $\begin{array}{l}\text { Self-realisation } \\
\text { Pleasure }\end{array}$ & The fulfilment of one's potential. \\
\hline
\end{tabular}

Figure 6 shows the change in QoL over the seven year period from Wave 1 to Wave 4, with each arrow representing this change. QoL did not decline linearly with age but instead increased from an average score of 27.9 at age 50 to a peak of 29.6 at age 68 . As the maximum score was 36 , this shows that overall, average QoL was high among TILDA participants. The largest decline in QoL over this period was generally observed in older ages. 
Figure 6. Change in quality of life (CASP-12) score over seven years from Wave 1 to Wave 4

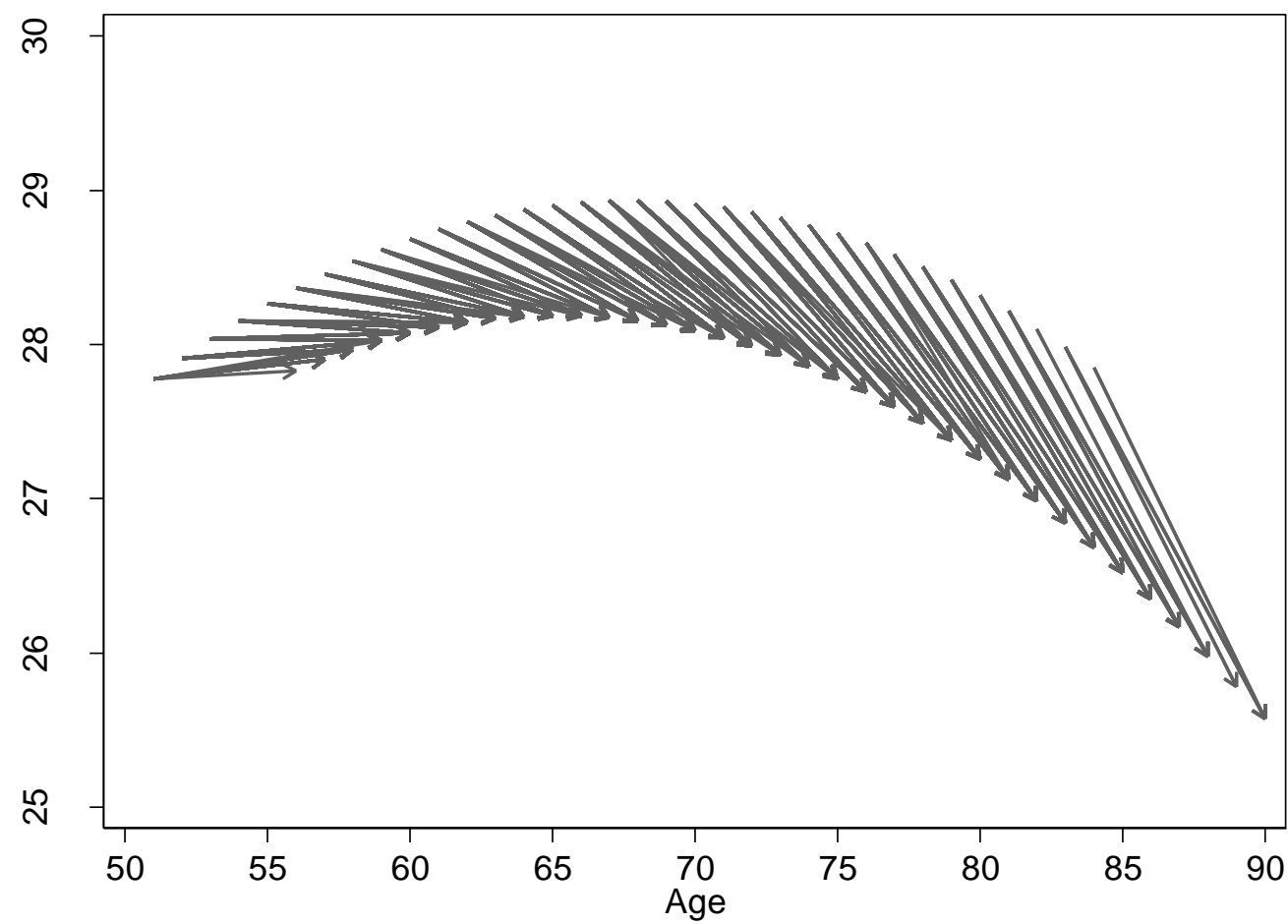

Overall, $44 \%$ (95\% Cl: $38.3-48.5$ ) of participants reported higher QoL after retirement while $43 \%$ (95\% Cl: 38.8-48.6) reported lower QoL. Table 5 shows the mean CASP-12 QoL score before and after retirement disaggregated by gender, age group, and retirement plans. There was little change in mean QoL scores before and after retirement although there was some evidence of an increase in QoL among those who were aged 50 to 55 years when they retired $(t(76)=-2.38, p<0.05)$.

Table 5. Mean CASP-12 QoL score before and after retirement by gender, age, and whether retirement was planned for

\begin{tabular}{|c|c|c|c|}
\hline & $\begin{array}{c}\text { Before retirement - } \\
\text { CASP-12 } \\
\text { Mean }(95 \% \mathrm{CI})\end{array}$ & $\begin{array}{c}\text { After retirement - } \\
\text { CASP-12 } \\
\text { Mean }(95 \% \mathrm{Cl}\end{array}$ & $\begin{array}{c}\text { Test statistic and } P \\
\text { value }\end{array}$ \\
\hline \multicolumn{4}{|l|}{ Gender } \\
\hline Men & $28.5[27.7,29.3]$ & $28.8[28.0,29.5]$ & $t(179)=-0.40$, n.s. \\
\hline Women & $29.4[28.6,30.2]$ & $29.2[28.4,30.0]$ & $t(198)=0.53$, n.s. \\
\hline \multicolumn{4}{|l|}{ Age group } \\
\hline $50-55$ years & $27.3[25.7,28.9]$ & $28.4[26.8,30.0]$ & $t(76)=-2.38, p<0.05$ \\
\hline $56-60$ years & $29.5[28.7,30.4]$ & $29.7[28.8,30.5]$ & $t(146)=-0.20$, n.s. \\
\hline $61-67$ years & $29.3[28.5,30.0]$ & $28.7[27.9,29.4]$ & $t(154)=1.78$, n.s. \\
\hline \multicolumn{4}{|l|}{ Retirement plans } \\
\hline Planned to retire & $29.0[28.3,29.6]$ & $29.1[28.5,29.7]$ & $t(308)=-0.04$, n.s. \\
\hline Did not plan to retire & $28.8[27.4,30.1]$ & $28.4[26.9,30.0]$ & $t(69)=0.29$, n.s. \\
\hline Total & $28.9[28.3,29.5]$ & $29.0[28.4,29.5]$ & $\mathrm{t}(378)=0.10$, n.s. \\
\hline
\end{tabular}


Figure 7 shows mean QoL scores at each Wave according to the timing of retirement. The steepest decrease in QoL was observed between Waves 1 and 3 among participants who were retired after Wave 3. Each of the groups showed a small increase in QoL scores between Waves 3 and 4 .

Figure 7. Mean CASP-12 Quality of Life score at each Wave by timing of retirement

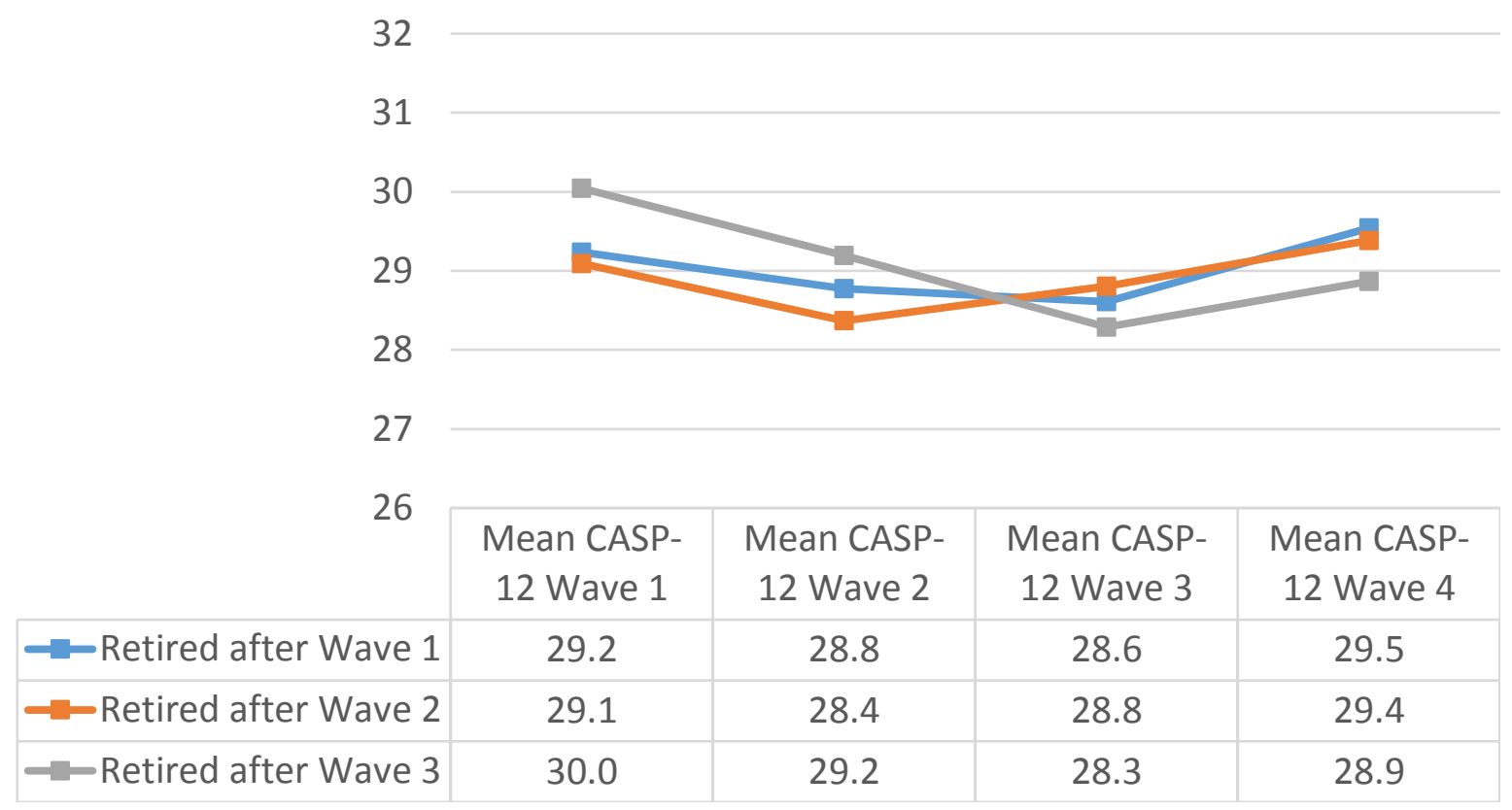

As well as assessing change in overall QoL, it is important to examine the four domains separately to identify if any particular feature(s) of QoL is impacted more by retirement. The only significant change in the four domains was the increase in self-realisation in men post-retirement.

Table 6. Mean CASP-12 QoL domain scores before and after retirement by gender

\begin{tabular}{|c|c|c|c|}
\hline & $\begin{array}{c}\text { Before retirement - } \\
\text { Mean }(95 \% \mathrm{CI})\end{array}$ & $\begin{array}{l}\text { After retirement - } \\
\text { Mean }(95 \% \mathrm{Cl}\end{array}$ & $\begin{array}{c}\text { Test statistic and } \mathbf{P} \\
\text { value }\end{array}$ \\
\hline \multicolumn{4}{|c|}{ Control (maximum score 12) } \\
\hline Men & $9.0[8.6,9.3]$ & $8.7[8.3,9.0]$ & $t(184)=1.2$, n.s. \\
\hline Women & $9.3[8.9,9.6]$ & $9.0[8.6,9.4]$ & $\mathrm{t}(207)=1.4$, n.s. \\
\hline \multicolumn{4}{|c|}{ Autonomy (maximum score 9) } \\
\hline Men & $6.5[6.2,6.7]$ & $6.6[6.3,6.8]$ & $\mathrm{t}(189)=-0.5$, n.s. \\
\hline Women & $6.8[6.5,7.0]$ & $6.8[6.5,7.0]$ & $t(215)=-0.3$, n.s. \\
\hline \multicolumn{4}{|c|}{ Pleasure (maximum score 9) } \\
\hline Men & $8.1[7.9,8.4]$ & $8.3[8.1,8.5]$ & $t(187)=-1.2$, n.s. \\
\hline Women & $8.3[8.0,8.5]$ & $8.2[7.9,8.4]$ & $\mathrm{t}(213)=0.6$, n.s. \\
\hline \multicolumn{4}{|c|}{ Self-realisation (maximum score 6) } \\
\hline Men & $4.9[4.8,5.1]$ & $5.1[4.9,5.3]$ & $T(190)=-2.4, p<0.05$ \\
\hline Women & $5.1[4.9,5.2]$ & $5.0[4.8,5.3]$ & $t(218)=-0.03$, n.s. \\
\hline
\end{tabular}




\subsection{Stress}

While there is some evidence that stress, particularly health-related stress increases with age [17], retired individuals have been found to have lower levels of stress than the employed [18]. However, the process of retirement may itself be stressful and may vary according to the type of occupation previously engaged in, and also reasons for, and expectations regarding retirement $[19,20]$. The absence of work-related stress has also been suggested as a potential mechanism through which retirement positively affects physical health [21].

Stress was measured at each Wave using the four-item version of the Perceived Stress Scale (PSS-4, [22]) which measures how unpredictable, uncontrollable, and overloaded a respondent's life is [23].

This measurement tool consists of the following four questions about participants feelings over the month prior to interview.

$>$ In the last month, how often have you felt that you were unable to control the important things in your life?

$>$ In the last month, how often have you felt confident about your ability to handle your personal problems?

$>$ In the last month, how often have you felt that things were going your way?

$>$ In the last month, how often have you felt difficulties were piling up so high that you could not overcome them?

The response categories to each question were: hardly ever, almost never, sometimes, fairly often, and very often. Responses were scored from zero for hardly ever to four for very often. These scores were then summed to give an overall perceived stress score that ranged from zero (least stress) to 16 (most stress)

As shown in Table 7, there was no significant change in perceived stress scores when participants moved from employment to retirement. 
Table 7. Mean Perceived Stress Score before and after retirement by gender, age, and whether retirement was planned for

\begin{tabular}{|c|c|c|c|}
\hline & $\begin{array}{c}\text { Before retirement - } \\
\text { Stress } \\
\text { Mean }(95 \% \mathrm{Cl})\end{array}$ & $\begin{array}{c}\text { After retirement - } \\
\text { Stress } \\
\text { Mean (95\% Cl }\end{array}$ & $\begin{array}{c}\text { Test statistic and } P \\
\text { value }\end{array}$ \\
\hline \multicolumn{4}{|l|}{ Gender } \\
\hline Men & $7.3[7.0,7.6]$ & $7.3[6.9,7.6]$ & $\mathrm{t}(189)=0.2$, n.s. \\
\hline Women & $7.4[7.1,7.7]$ & $7.3[7.0,7.6]$ & $\mathrm{t}(212)=0.4$, n.s. \\
\hline \multicolumn{4}{|l|}{ Age group } \\
\hline $50-55$ years & $7.8[7.4,8.2]$ & $7.6[7.2,7.9]$ & $\mathrm{t}(75)=1.0$, n.s. \\
\hline $56-60$ years & $7.4[7.1,7.8]$ & $7.6[7.2,7.9]$ & $t(153)=-1.1$, n.s. \\
\hline $61-67$ years & $7.1[6.7,7.5]$ & $6.9[6.6,7.3]$ & $\mathrm{t}(172)=1.1$, n.s. \\
\hline \multicolumn{4}{|l|}{ Retirement plans } \\
\hline Planned to retire & $7.4[7.2,7.6]$ & $7.3[7.1,7.6]$ & $\mathrm{t}(326)=0.6$, n.s. \\
\hline Did not plan to retire & $7.0[6.4,7.6]$ & $7.1[6.6,7.6]$ & $t(75)=-0.3$, n.s. \\
\hline Total & $7.3[7.1,7.6]$ & $7.3[7.1,7.5]$ & $\mathrm{t}(402)=0.4$, n.s. \\
\hline
\end{tabular}

\section{Retirement and social participation}

\subsection{Volunteering}

Given the comparatively high rates of volunteering in Ireland [24], it is possible that individuals may be more likely to participate in voluntary activities following retirement. We see if an initiation or an increase in voluntary or other forms of social participation occurs in the newly retired who may have previously been precluded due to the time constraints inherent in paid employment.

Overall, 37.5\% (95\% Cl: 34.8-40.2) of employed participants at Wave 1 did not volunteer in the previous 12 months, 31.7\% (95\% Cl: 29.2-34.3) volunteered less than monthly, 15.4\% (95\% Cl: 13.617.3) did so monthly, while $15.5 \%(95 \% \mathrm{Cl}$ : 13.6-17.6) volunteered at least weekly. Figure 8 shows the percentage of participants (who were employed at Wave 1 and aged less than 68 years) who volunteered at least once in the previous year. While there was little overall change across the Waves, we do see some evidence of an increase in the percentage of participants who volunteered immediately after retirement. In particular, we see an increase from $57.1 \%$ to $65.5 \%$ among those who retired after Wave 2. A similar pattern is observed among participants who retired after Wave 3 with an increase from $62.5 \%$ to $67.0 \%$. However, it must be noted that these increases did not reach statistical significance. 
Figure 8. Percentage of participants who volunteered before and after retirement

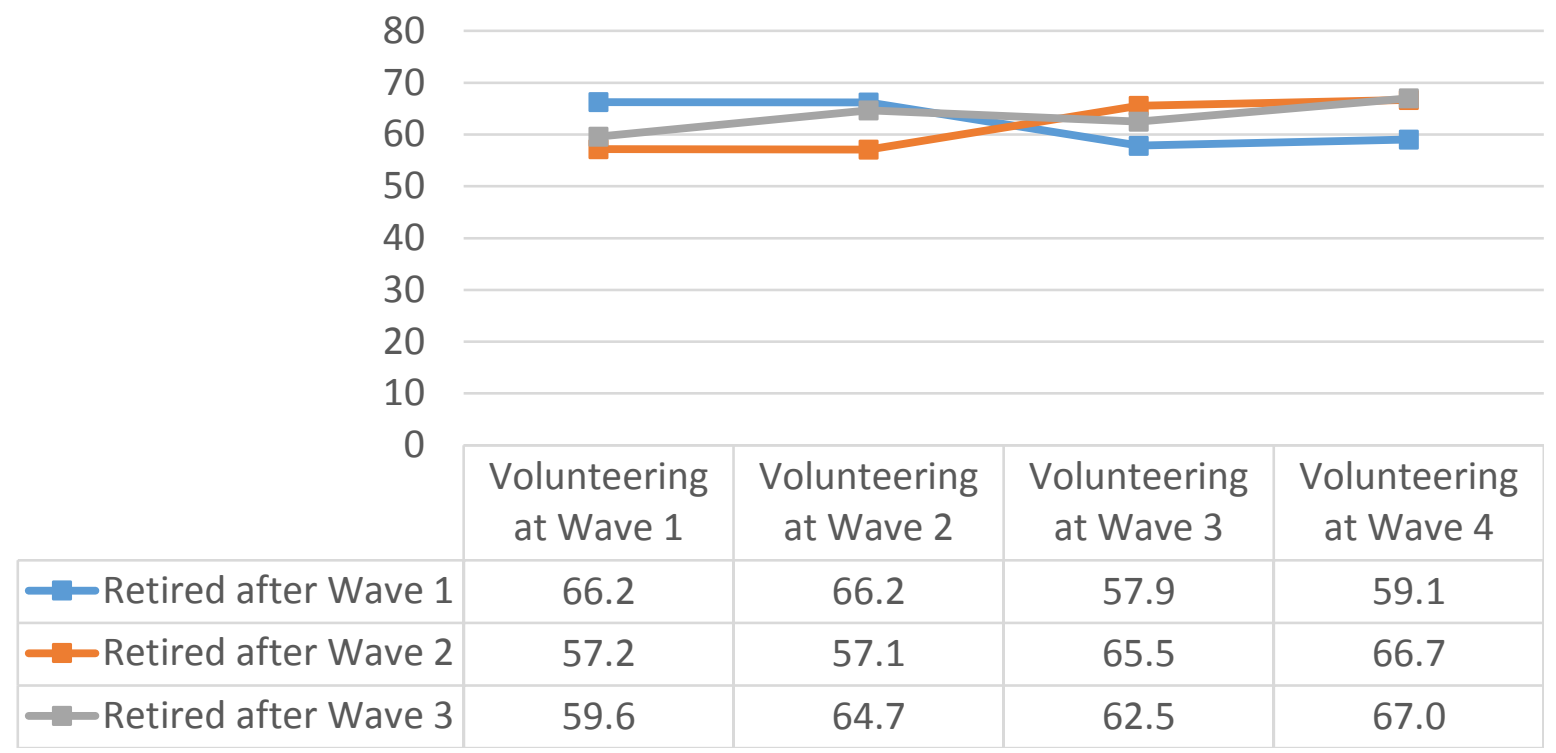

Figure 9 includes participants who were employed and volunteered at least once per year at Wave 1 and shows the percentage of these volunteers who decreased, increased, or did not change how often they volunteered. Men tended to maintain the same frequency of volunteering after retirement, while women were more likely to increase their frequency of volunteering once retired, particularly those who had worked in the private sector.

Figure 9. Change in frequency of volunteering among participants who volunteered at Wave 1 and retired over the course of TILDA

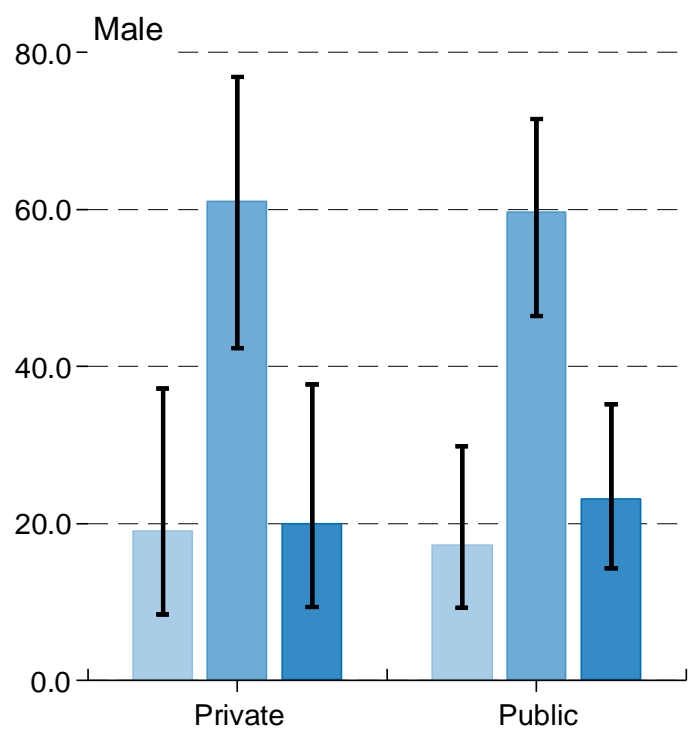

Female

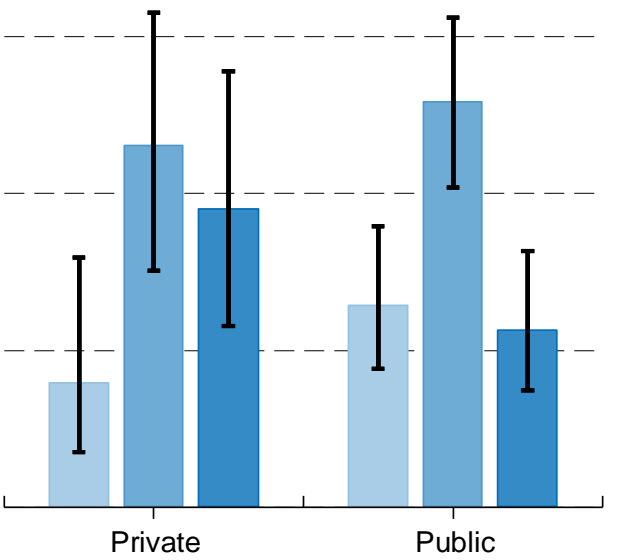

Less volunteering

No change

More frequent volunteering 
Table 8 shows the percentage of participants who volunteered at least weekly before and after retirement, broken down by gender, age group, and retirement plans. Overall, the percentage of participants who volunteered weekly increased after retirement from $14.5 \%$ (95\% Cl: $11.2-18.5)$ to $22.2 \%$ (95\% Cl: 18.2-26.9). This pattern was observed among all groups although the increase among the 50 to 55 year old age group and those with no retirement plans did not reach statistical significance. The largest increase was found among women with the percentage volunteering weekly increasing from $13.8 \%$ (95\% Cl: 9.7-19.3) while employed to $22.6 \%$ (95\% Cl: 17.2-29.2) when retired.

Table 8. Percentage who volunteered at least weekly before and after retirement by gender, age, and whether retirement was planned for

\begin{tabular}{|c|c|c|c|}
\hline & $\begin{array}{c}\text { Before retirement - } \\
\% \text { volunteered } \\
\text { Mean }(95 \% \mathrm{CI})\end{array}$ & $\begin{array}{c}\text { After retirement - } \\
\% \text { volunteered } \\
\text { Mean }(95 \% \mathrm{Cl}\end{array}$ & $\begin{array}{c}\text { Test statistic and } \mathbf{P} \\
\text { value }\end{array}$ \\
\hline \multicolumn{4}{|l|}{ Gender } \\
\hline Men & $15.1[10.5,21.2]$ & $21.9[16.4,28.6]$ & $\chi^{2}(1)=5.5, p<0.05$ \\
\hline Women & $13.8[9.7,19.3]$ & $22.6[17.2,29.2]$ & $\chi^{2}(1)=5.5, p<0.05$ \\
\hline \multicolumn{4}{|l|}{ Age group } \\
\hline $50-55$ years & $15.1[8.8,24.8]$ & $20.1[12.5,30.7]$ & $\chi^{2}(1)=0.6$, n.s. \\
\hline $56-60$ years & $12.6[7.9,19.4]$ & $20.9[14.9,28.4]$ & $\chi^{2}(1)=5.5, p<0.05$ \\
\hline 61-67 years & $15.8[10.6,22.8]$ & $24.2[17.9,31.9]$ & $\chi^{2}(1)=5.5, p<0.05$ \\
\hline \multicolumn{4}{|l|}{ Retirement plans } \\
\hline Planned to retire & $13.6[10.2,18.0]$ & $21.7[17.4,26.7]$ & $\chi^{2}(1)=9.3, p<0.01$ \\
\hline Did not plan to retire & $18.1[10.7,29.0]$ & $24.8[15.8,36.6]$ & $\chi^{2}(1)=1.6$, n.s. \\
\hline Total & $14.5[11.2,18.5]$ & $22.2[18.2,26.9]$ & $\chi^{2}(1)=10.9, p<0.01$ \\
\hline
\end{tabular}

\subsection{Active and social leisure activities}

Participation in active and social leisure activities included: attending films, plays, concerts, classes, lectures; playing cards, bingo, games; socialising in the pub; eating out; participating in sports and exercise. We examined each individual activity and participation in any of these six activities. With more time available to participants to pursue social activities once they have retired from paid employment, we expect to see increased participation in these activities.

Overall, 76.5\% (95\% Cl: 71.5-80.8) of participants took part in at least one of these activities each week while employed and this increased to $83.0 \%$ (95\% Cl: 78.2-86.9) after retirement. Participation in sports and exercise was the most popular activity while employed and after retirement (Table 9). The percentage of participants who took part in each activity post-retirement increased after retirement, with the exception of eating out. These increases were statistically significant for three of the activities. The percentage of participants who attended classes or lectures was $7.1 \%(95 \% \mathrm{Cl}$ : 4.8-10.4) while employed and $12.0 \%(95 \% \mathrm{Cl}: 8.9-16.0)$ after retirement. The percentage who took 
part in card games and games such as bingo increased from $14.0 \%(95 \% \mathrm{Cl}: 4.8-10.4)$ while employed to $18.7 \%(95 \% \mathrm{Cl}: 14.9-23.2)$ after retirement. Participation in sports and exercise also increased, from $64.3 \%$ (95\% Cl: 58.9-69.4) to $70.5 \%$ (95\% Cl: 65.4-75.1).

Table 9. Weekly active and social leisure activities before and after retirement

\begin{tabular}{lccl} 
& $\begin{array}{c}\text { Before retirement - } \\
\%(95 \% \mathrm{CI})\end{array}$ & $\begin{array}{c}\text { After retirement }- \\
\%(95 \% \mathrm{CI})\end{array}$ & $\begin{array}{c}\text { Test statistic and P } \\
\text { value }\end{array}$ \\
\hline Films, plays, concerts & $1.2[0.4,3.1]$ & $1.5[0.6,3.5]$ & $\chi^{2}(1)=0.1$, n.s. \\
Classes, lectures & $7.1[4.8,10.4]$ & $12.0[8.9,16.0]$ & $\chi^{2}(1)=4.6, p<0.05$ \\
\hline Cards, bingo, games & $14.0[10.7,18.0]$ & $18.7[14.9,23.2]$ & $\chi^{2}(1)=5.4, p<0.05$ \\
\hline Pub & $21.3[17.1,26.0]$ & $22.6[18.3,27.6]$ & $\chi^{2}(1)=0.8$, n.s. \\
Eat out & $18.4[14.3,23.3]$ & $16.8[12.9,21.7]$ & $\chi^{2}(1)=0.6$, n.s. \\
Sports, exercise & $64.3[58.9,69.4]$ & $70.5[65.4,75.1]$ & $\chi^{2}(1)=9.1, p<0.01$ \\
\hline Any activity & $76.5[71.5,80.8]$ & $83.0[78.2,86.9]$ & $\chi^{2}(1)=12.6, p<0.001$
\end{tabular}

As well as personal characteristics such as personal preferences and disposition, participation in many of these activities depends on accessibility. For example, cinemas and theatres tend to be located in urban centres and therefore may not be easily accessed by rural populations, particularly if individuals do not have their own transport and are poorly served by public transport. Therefore, Table 10 shows the percentage of participants taking part in active and social leisure activities separately for urban and rural participants. For both urban and rural participants, activities related to sports and exercise were the most popular and attending films, plays and concerts the least popular. As shown in Table 10, a higher percentage of participants in urban areas took part in at least one activity every week compared to those in rural areas, both before and after retirement although the difference between the two was smaller post-retirement. Overall participation in these activities increased among both cohorts post-retirement.

Employed, urban participants were more likely to attend films, plays and concerts; attend classes or lectures; and take part in sports and exercise while rural participants were slightly more likely to participate in card games, go to the pub weekly, and eat out. Urban participants were also more likely to attend classes or lectures and play card games after retirement. The biggest change observed among rural participants was in sports and exercise which increased from $59.6 \%(95 \% \mathrm{Cl}$ : 51.4-67.4) while employed to $66.2 \%$ (95\% $\mathrm{Cl}: 57.8-73.7)$ in retirement. 
Table 10. Weekly active and social leisure activities before and after retirement by urban / rural

\begin{tabular}{|c|c|c|c|c|}
\hline & & $\begin{array}{c}\text { Before retirement - } \\
\%(95 \% \mathrm{Cl})\end{array}$ & $\begin{array}{c}\text { After retirement - } \\
\%(95 \% \mathrm{CI})\end{array}$ & $\begin{array}{c}\text { Test statistic and } \mathbf{P} \\
\text { value }\end{array}$ \\
\hline \multirow[t]{2}{*}{ Films, plays, concerts } & Urban & $1.5[0.5,4.1]$ & $1.3[0.4,4.3]$ & $\chi^{2}(1)=0.33$, n.s. \\
\hline & Rural & $0.4[0.0,2.7]$ & $1.8[0.6,5.5]$ & $\chi^{2}(1)=1.0$, n.s. \\
\hline \multirow[t]{2}{*}{ Classes, lectures } & Urban & $8.0[5.2,12.2]$ & $12.3[8.7,17.2]$ & $\chi^{2}(1)=4.0, p<0.05$ \\
\hline & Rural & $4.8[2.4,9.4]$ & $8.2[4.8,13.6]$ & $\chi^{2}(1)=0.8$, n.s. \\
\hline \multirow[t]{2}{*}{ Cards, bingo, games } & Urban & $14.4[10.1,20.1]$ & $23.2[17.8,29.5]$ & $\chi^{2}(1)=11.8, p<0.001$ \\
\hline & Rural & $16.3[11.2,23.2]$ & $15.9[10.6,23.2]$ & $\chi^{2}(1)=0.2$, n.s. \\
\hline \multirow[t]{2}{*}{ Pub } & Urban & $20.9[15.7,27.2]$ & $21.6[16.4,27.8]$ & $\chi^{2}(1)=0.1$, n.s. \\
\hline & Rural & $23.6[17.2,31.4]$ & $25.6[18.6,34.1]$ & $\chi^{2}(1)=2.6$, n.s. \\
\hline \multirow[t]{2}{*}{ Eat out } & Urban & $14.5[10.5,19.7]$ & $13.1[9.1,18.5]$ & $\chi^{2}(1)=0.1$, n.s. \\
\hline & Rural & $20.8[14.6,28.6]$ & $19.5[13.7,27.0]$ & $\chi^{2}(1)=0.6$, n.s. \\
\hline \multirow[t]{2}{*}{ Sports, exercise } & Urban & $66.4[59.4,72.7]$ & $73.2[66.7,78.8]$ & $\chi^{2}(1)=5.1, p<0.05$ \\
\hline & Rural & $59.6[51.4,67.4]$ & $66.2[57.8,73.7]$ & $\chi^{2}(1)=4.0, p<0.05$ \\
\hline \multirow[t]{2}{*}{ Any activity } & Urban & $78.7[72.3,83.9]$ & $84.4[78.7,88.7]$ & $\chi^{2}(1)=4.9, p<0.05$ \\
\hline & Rural & $72.1[64.5,78.6]$ & $81.7[73.5,87.7]$ & $\chi^{2}(1)=8.3, p<0.01$ \\
\hline
\end{tabular}

\section{Retirement and caregiving}

Due in large part to high financial costs associated with formal childcare in Ireland, families with preschool aged children in particular are often heavily reliant on grandparents to provide both regular and irregular childcare [25]. Regular childcare is often necessary for mothers' labour market participation while irregular childcare is needed due to unanticipated events $[26,27]$. While many older adults provide regular and / or irregular childcare even when they are employed, it is likely that many caregivers take on extra childcare responsibilities once retired. To assess the validity of this assumption, we describe the percentage of participants who provide regular childcare to grandchildren or great grandchildren before and after retirement. We also estimate the number of hours of care that is provided.

As well as caring for grandchildren, many older adults provide regular care to their own parents/relatives. Previous research using TILDA data reported that $23 \%$ of participants who had living parents provided help with personal care for an average of 23 hours per week and $43 \%$ assisted with other activities such as shopping and doing household chores for 13 hours each week.

At every Wave of data collection, TILDA collects detailed information on the type and intensity of care provided by participants to their parents. Participants were asked if they provided regular care to their own parent(s) because of any difficulties with Activities of Daily Living (ADLs) and/or Instrumental Activities of Daily Living (IADLs). ADLs included difficulties with dressing, walking across a room, bathing or showering, eating, getting in or out of bed, and using the toilet, while IADLs 
included preparing meals, doing household chores, shopping, using the telephone, taking medications, and managing money.

Over half (53.7\% 95\% Cl: 47.0-60.2) of employed participants cared for grandchildren for a minimum of one hour per week, with similar figures pre- and post-retirement (Table 11). However, we do see a trend for an increase in the average number of hours that care is provided for from 27.8 hours a month (95\% Cl: 22.3-33.4) while employed to 37.6 hours (95\% Cl: 29.3-45.8) when retired.

Overall, 57.5\% (95\% Cl: 47.3-67.0) of employed participants provided help with ADLs or IADLs and 49.1\% (95\% Cl: 37.6-60.8) did so when retired. This decrease was in part driven by the fact that many parents of participants died during this period.

Unfortunately, due to the small number of our sample providing this type of care it was not possible to accurately estimate any change in the number of hours that care was provided for.

Table 11. Percentage and number of hours cared for grandchildren or parents with an ADL or IADL before and after retirement

\begin{tabular}{|c|c|c|c|}
\hline & $\begin{array}{l}\text { Before retirement - } \\
\quad \%(95 \% \mathrm{Cl})\end{array}$ & $\begin{array}{l}\text { After retirement - } \\
\%(95 \% \mathrm{Cl})\end{array}$ & $\begin{array}{c}\text { Test statistic and } \mathbf{P} \\
\text { value }\end{array}$ \\
\hline \multicolumn{4}{|c|}{ Cared for grandchildren } \\
\hline$\%$ who cared for & $53.7[47.0,60.2]$ & $51.7[45.5,57.9]$ & $\chi^{2}(1)=0.2$, n.s. \\
\hline $\begin{array}{l}\text { Average hours cared for } \\
\text { per month }\end{array}$ & $27.8[22.3,33.4]$ & $37.6[29.3,45.8]$ & $t(111)=-2.3, p<0.05$ \\
\hline \multicolumn{4}{|c|}{ Cared for parent/relative } \\
\hline$\%$ who cared for (ADLs) & $30.7[22.3,40.7]$ & $29.2[19.8,40.8]$ & $\chi^{2}(1)=0.2$, n.s. \\
\hline$\%$ who cared for (IADLs) & $53.4[43.1,63.5]$ & $46.6[35.1,58.4]$ & $\chi^{2}(1)=1.0$, n.s. \\
\hline$\%$ who cared for (All) & $57.5[47.3,67.0]$ & $49.1[37.6,60.8]$ & $\chi^{2}(1)=1.6$, n.s. \\
\hline
\end{tabular}

\section{Retirement and health-related behaviours}

In this final section we discuss the effect of retirement on two health-related behaviours - walking and smoking. Physical activity is associated with a wide range of benefits. For example, TILDA has previously shown that higher levels of physical activity are associated with greater participation in social activities, better self-rated health, and quality of life, and lower loneliness scores [28]. Furthermore, regular moderate physical activity such as walking, cycling, playing sport, or gardening can significantly reduce the risk of cardiovascular disease, diabetes, colon and breast cancer and depression, as well as helping to maintain a healthy body weight [29]. 


\subsection{Walking}

The World Health Organisation recommend that adults should undertake at least 30 minutes a day of moderate intensity activity on 5 days a week (or 150 minutes per week). Brisk walking is one of the easiest ways to achieve this target. Adults aged 65 and older are also advised to add activities which increase muscular strength and balance on two-to-three days per week to reduce their risk of falls [29]. These guidelines have been adopted in the National Physical Activity Plan for Ireland [30].

TILDA participants were asked to indicate the number of days on which they walked for at least 10 minutes at a time in the last week and how long they usually spent walking on those days. The number of days was multiplied by the number of minutes to estimate the total number of minutes that participants walked for in the last week.

Participants were also categorised $p$ according to whether or not they walked for a minimum of 150 minutes or not. We have split the analysis by urban / rural to take account of differences in walkability and other characteristics of the physical environment.

Overall, two-thirds of adults walked for at least 150 minutes per week both before and after retirement, although retired individuals walked less than those in employment. Different trends were observed between those living in urban and rural areas, particularly after retirement when more urban dwellers achieved the 150 minutes per week target but fewer rural dwellers achieved the target. There was also a trend for those in rural areas to walk for a shorter duration over the week.

Table 12. Average minutes walking per week and percentage exceeding the recommended 150+ minutes per week activities before and after retirement

\begin{tabular}{lccl} 
& Before retirement & After retirement & $\begin{array}{c}\text { Test statistic and } \mathbf{P} \\
\text { value }\end{array}$ \\
\hline Mean minutes All & $379[328,431]$ & $330[289,371]$ & $\mathrm{t}(411)=2.00, \mathrm{p}<0.05$ \\
\hline$\%>150$ minutes All & $65.0[59.8,69.8]$ & $65.8[60.8,70.4]$ & $\chi^{2}(1)=0.0$, n.s. \\
\hline Mean minutes Urban & $348[288,407]$ & $338[288,387]$ & $\mathrm{t}(244)=0.2$, n.s. \\
\hline Mean minutes Rural & $435[336,534]$ & $317[245,388]$ & $\mathrm{t}(166)=2.4, \mathrm{P}<0.05$ \\
$\%>150$ minutes Urban & $64.6[57.9,70.8]$ & $72.4[66.4,77.7]$ & $\chi^{2}(1)=4.6, \mathrm{P}<0.05$ \\
$\%>150$ minutes Rural & $65.6[57.2,73.2]$ & $54.2[46.0,62.2]$ & $\chi^{2}(1)=4.3, \mathrm{P}<0.05$
\end{tabular}

\subsection{Smoking}

Smoking is a well-known risk factor for a variety of adverse health condition including cardiovascular disease, lung disease, and other chronic conditions [31]. Prevalence rates of smoking are at an alltime low in Ireland and continuing to fall [32], in no small part due to sustained public health strategies such as the Tobacco Free Ireland policy introduced in 2013 [33]. 
Previous evidence indicates that transitioning to retirement provides a stage of the life-cycle when individuals often modify their health-related behaviours, including smoking [8,34], however, we found no difference in smoking prevalence before (11.5\%, 95\% Cl: 8.6-15.2) and after retirement (11.1\%, 95\% Cl: 8.2-15.0].

Figure 10 shows the percentage of smokers at each Wave according to their retirement transition. This enables us to see if there was a decrease in prevalence immediately after retirement or if there was a lag before individuals stopped smoking. Again, the general pattern is for small reductions in the percentage of smokers and there is some limited evidence of an association with transitioning to retirement as we see a reduction immediately after retirement among those who retired after Wave 1 and Wave 2.

Figure 10. Percentage of participants who smoked at each Wave before and after retirement

$$
25
$$

20

15

10

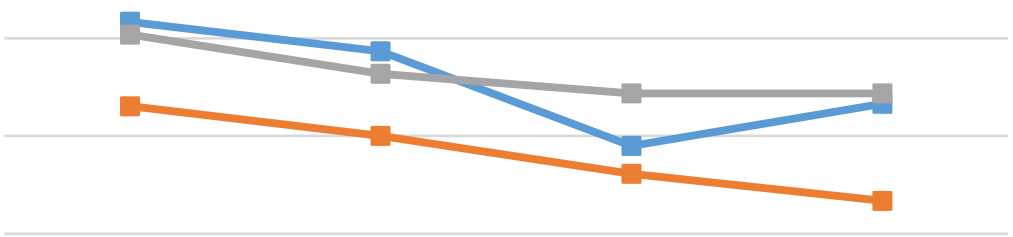

5

\begin{tabular}{|l|c|c|c|c|}
\multicolumn{1}{c|}{0} & $\begin{array}{c}\text { Smokers at } \\
\text { Wave 1 }\end{array}$ & $\begin{array}{c}\text { Smokers at } \\
\text { Wave 2 }\end{array}$ & $\begin{array}{c}\text { Smokers at } \\
\text { Wave 3 }\end{array}$ & $\begin{array}{c}\text { Smokers at } \\
\text { Wave 4 }\end{array}$ \\
\hline -E-Employed at Wave 1 only & 15.8 & 14.3 & 9.5 & 11.6 \\
\hline - E-Employed up to Wave 2 & 11.5 & 10.0 & 8.1 & 6.7 \\
\hline- -Employed up to Wave 3 & 15.2 & 13.2 & 12.2 & 12.2 \\
\hline
\end{tabular}




\section{Discussion}

In this report we have described the transition from employment to retirement of TILDA participants between 2009 and 2016. We have described employed participants' plans for retirement (age at which they plan to retire and pension coverage) and examined the impact of retirement on quality of life, stress, social participation, caregiving, and health-related behaviours. Our main interest was in the transition from employment to retirement therefore our main analyses focused on participants who were employed at Wave 1 and for whom we had valid employment data available for each of the first four Waves of TILDA. Furthermore, in order to reflect the pension system, our analyses was limited to participants who were employed and aged 67 years and younger during Wave 1 of data collection which began in 2009.

We found that a majority of employed participants planned to retire before the age of 68 and that most were enrolled in either an occupational pension scheme organised by their employer or were members of a PRSA/other personal pension scheme. Pension coverage was intrinsically linked to retirement planning; employees with no firm plans for when they hoped to retire were the group most likely to have no pension coverage.

Moving from employment had a minimal impact on overall quality of life. However, we did find that retirement was associated with an increased score in the self-realisation domain which supports the belief that retirement can result in more opportunities to pursue activities outside of work.

Previous research suggested that we might expect to see some change in stress, either positive or negative following retirement [18-20]. For example, we might have observed a decrease in stress among participants who retired from psychologically or physically demanding jobs and an increase among those who may not have been prepared for the change to retirement. While it was not possible to explicitly test differences between physically demanding and sedentary occupation, overall we did not observe any change in reported stress as people moved from employment to retirement. This may be a statistical artefact whereby the number of cases included in the analysis limited the possibility of observing significant changes. Alternatively, it may be that the frame of reference employed by respondents to these questions is focused on events or experiences outside the domain of work. Another possible explanation is that the time interval between retirement and our measuring of perceived stress may be too short in the current analyses. Future research on the potential association between perceived stress and the transition to retirement may benefit from considering a longer timeframe whereby retirees will have been afforded more time to adjust to their new role. It may also prove productive to consider in finer detail the physical and psychological demands of the occupation from which individuals have retired. 
TILDA has previously shown high rates of volunteering among older adults in Ireland and that volunteering and other forms of social participation are associated with better quality of life and fewer depressive symptoms. Therefore, these activities are an important feature of successful ageing [35]. Beyond the benefits of volunteering to the individual, the fact that more than half of older adults volunteered their time and expertise at some stage, and almost one-in-five do so on a weekly basis, shows the considerable contribution that older adults make to the economic, social, and cultural life in their communities.

While there was little evidence of an increase in the percentage of participants volunteering after retirement, there was a noteworthy increase in those volunteering weekly after retirement amongst those already volunteering. . This suggests that few people start volunteering after retirement but those that volunteered regularly while employed increase their frequency of volunteering once retired. This suggests that behaviours or habits, such as volunteering, may be established in earlier adulthood.

There are a number of potential reasons why people do not replace some of the time previously spent in employment with voluntary work. Many participants may prefer not to replace paid employment with activities such as volunteering. Equally, personal characteristics such as sociability, physical and psychological wellbeing, or education may act as a barrier against volunteering. There may also be structural reasons such as a lack of opportunities for social participation, or indeed, a lack of information about available opportunities. These potential structural barriers are amenable to public policy interventions and could be resolved by ensuring that information is available and adapting communication of public awareness campaigns to better target older adults. A simple example of how this might work in practice is the scenario wherein a lack of information about opportunities to contribute to voluntary groups is identified as problematic. This barrier might be effectively overcome by adapting communication of public awareness campaigns to better target older adults.

High rates of participation in active and social leisure activities suggests that a large majority of older adults maintain active friendships and kinship into middle and older age. There was an increase in overall participation rates in active and social leisure activities and importantly this report has highlighted some important differences in the types of participation activities between urban and rural participants. While some of these differences may be due to personal preferences and proximal group norms, they may also be driven by differences in the availability of and access to different activities. 
This report has again highlighted the important role that older adults play as care providers to both their parents and grandchildren. The breadth of these contributions are substantial and demonstrate the important, but often hidden contribution that older adults make to the lives and wellbeing of both older and younger generations.

While there was no change in the proportion of people providing these different forms of care, the frequency of care provided, as measured by the number of hours spent caring, increased upon retirement. This highlights the burden of informal care that falls on our older adults and is something that policy makers must be cognisant of, particularly in the context of an ageing population.

Lastly, in terms of health-related behaviours, we found that the percentage of participants who achieved the recommended target of 150 minutes walking per week decreased among rural participants and increased among urban dwellers after retirement. Therefore, it appears that work provided rural participants in particular with opportunities for physical activity in the form of walking that are not available to them once retired. Further analysis where potential confounding factors that might explain this association are considered is required to test this hypothesis.

In summary, TILDA provides a unique opportunity to observe changes in the lives of older adults as they embark on retirement, an important stage of the life course. We have highlighted some of the areas which are affected to a lesser or greater extent by retirement and have also shown how individuals experience of the transition to retirement varies according to their preparedness for retirement and the context of their retirement including the age at which they retire and their location. Public policy must be mindful of this myriad of issues particularly in light of increasingly forceful calls for working lives to be extended as a response to ageing populations. 


\section{Appendix A}

Table A.1. CASP-12 Quality of Life domains and items

CASP-12 Quality of Life domains

My age prevents me from doing the things I would like to

Control I feel that what happens to me is out of my control

I feel free to plan for the future

I feel left out of things

I feel that I can please myself what I can do

Autonomy My health stops me from doing the things I want to do

Shortage of money stops me from doing the things that

I look forward to each day

Self-realisation I feel that my life has meaning

I enjoy being in the company of others

I feel satisfied with the way my life has turned out

Pleasure I feel that life is full of opportunities 


\section{Bibliography}

1. Kim JE, Moen P. Is Retirement Good or Bad for Subjective Well-Being? Curr Dir Psychol Sci. 2001;10(3):83-6.

2. Nivakoski S, Barrett A. Supplementary Pensions and the Income of Ireland's Retirees. Dublin: Trinity College Dublin; 2012.

3. Nivakoski S. Determinants of Pension Coverage and Retirement Income Replacement Rates Evidence from TILDA. Econ Soc Rev (Irel). 2014;45(3):299-328.

4. Weiss RS. The Experience of Retirement. New York: Cornell University Press; 2005.

5. Van den Bogaard L, Henkens K, Kalmijn M. So now what ? Effects of retirement on civic engagement. Ageing Soc. 2013;34:1170-92.

6. de Vaus $D$, Wells $Y$, Kendig H, Quine S. Does gradual retirement have better outcomes than abrupt retirement? Results from an Australian panel study. Ageing Soc. 2007;27(5):667-82.

7. Mosca I, Barrett A. The Impact of Voluntary and Involuntary Retirement on Mental Health : Evidence from Older Irish Adults. J Ment Health Policy Econ. 2016;19(1):33-44.

8. Lang IA, Rice NE, Wallace RB, Guralinka J, Melzer D. Smoking cessation and transition into retirement: analyses from the English Longitudinal Study of Ageing. Age Ageing. 2007;36:638-43.

9. Barnett I, Sluijs EMF Van, Ogilvie D. Physical Activity and Transitioning to Retirement: A systematic review. Am J Prev Med. 2012;43(3):329-36.

10. Nooyens ACJ, Visscher TLS, Schuit AJ, Van CTM, Verschuren WMM, Mechelen W Van, et al. Effects of retirement on lifestyle in relation to changes in weight and waist circumference in Dutch men : a prospective study. Public Health Nutr. 2005;8(8):1266-74.

11. Barrett A, Mosca I. Increasing the State Pension Age, the Recession and Expected Retirement Ages. Econ Soc Rev (Irel). 2013;44(4):447-72.

12. House J, Robbins $\mathrm{CMH}$. The association of social relationships and activities with mortality: Prospective evidence from the Tecumseh Community Health Study. Am J Epidemiol. 1982;116:123-40.

13. Ward M, McGarrigle CA, Kenny RA. More than health : quality of life trajectories among older adults - findings from The Irish Longitudinal Study on Ageing ( TILDA ). Qual Life Res. 2019;28(2):429-39.

14. Layte R, Sexton E, Savva G. Quality of life in older age: Evidence from an Irish cohort study. J Am Geriatr Soc. 2013;61(SUPPL2):299-305.

15. Sexton E, King-Kallimanis BL, Conroy RM, Hickey A. Psychometric evaluation of the CASP-19 quality of life scale in an older Irish cohort. Qual Life Res. 2013;22(9):2549-59.

16. Wiggins RD, Netuveli G, Hyde M, Higgs P, Blane D. The evaluation of a self-enumerated scale of quality of life (CASP-19) in the context of research on ageing: A combination of exploratory and confirmatory approaches. Soc Indic Res. 2008;89(1):61-77.

17. Osmanovic-Thunström A, Mossello E, Åkerstedt T, Fratiglioni L, Wang H. Do levels of perceived stress increase with increasing age after age 65 ? A population-based study. Age Ageing. 2015;44:828-34. 
18. Lindwall M, Berg Al, Bjälkebring P, Buratti S, Hansson I, Hassing L, et al. Psychological Health in the Retirement Transition: Rationale and First Findings in the HEalth, Ageing and Retirement Transitions in Sweden (HEARTS) Study. Front Psychol. 2017;8(September):1-13.

19. Salami SO. Retirement context and psychological factors as predictors of well-being among retired teachers. Eur J Psychol. 2010;6(2):47-64.

20. Nuttman-shwartz O. Like a High Wave : Adjustment to Retirement. Gerontologist. 2004;44(2):229-36.

21. Eibich P. Understanding the effect of retirement on health: Mechanisms and heterogeneity. J Health Econ. 2015;43:1-12.

22. Cohen S, Kamarck T, Mermelstein R. A Global Measure of Perceived Stress. J Health Soc Behav. 1983;24(4):385-96.

23. Feeney J, Sullivan MO, Kenny RA, Robertson IH. Change in perceived stress and 2-year change in cognitive function among older adults: The Irish Longitudinal Study on Ageing. Stress Heal. 2018;34:403-10.

24. Department of Health. Positive Ageing 2016. National Indicators Report. Dublin: Department of Health; 2016.

25. Röder A, Ward M, Frese C-A. From labour migrant to stay-at-home mother? Childcare and return to work among migrant mothers from the EU Accession countries in Ireland. Work Employ Soc. 2017;32(5):850-67.

26. Compton J, Pollak RA. Family proximity, childcare, and women's labor force attachment. J Urban Econ. 2014;79:72-90.

27. McNally S, Share M, Murray A. Prevalence and Predictors of Grandparent Childcare in Ireland: Findings from a Nationally Representative Sample of Infants and their Families. Child Care Pract. 2014;20(2):182-93.

28. Donoghue $\mathrm{O}, \mathrm{O}$ 'Connell M, Kenny RA. WALKING TO WELLBEING: Physical Activity, Social Participation and Psychological Health in Irish adults aged 50 years and Older. Dublin: The Irish Longitudinal Study on Ageing (TILDA); 2016.

29. WHO. Physical activity strategy for the WHO European Region 2016-2025. WHO. Copenhagen; 2015.

30. Department of Health. The National physical activity plan for Ireland. Dublin: Department of Health; 2013.

31. Wald NJ, Hackshaw AK. Cigarette smoking : an epidemiological overview. Br Med Bull. 1996;32(1):3-11.

32. Hickey A, Evans D. Smoking in Ireland 2014: Synopsis of Key Patterns. Dublin: health Service Executive; 2015.

33. Department of Health. Tobacco Free Ireland. Report of the Tobacco Policy Review Group. Dublin: Department of Health; 2013.

34. Pulakka A, Halonen JI, Pentti J, Kivimäki M, Vahtera J, Stenholm S. Changes in Smoking During Retirement Transition: A Longitudinal Cohort Study. Scand J Public Health. 2018;1-9.

35. Ward M, McGarrigle C. The Contribution of Older Adults to their Families and Communities. In: McGarrigle C, Donoghue O, Scarlett S, Kenny RA, editors. Health and Wellbeing : Active 
Ageing for Older Adults in Ireland Evidence from The Irish Longitudinal on Ageing. Dublin: The Irish Longitudinal on Ageing (TILDA); 2017. 